\title{
Synthesis, Biological Evaluation and Structure Activity Relationship of Substituted pyrazolo-, isoxazolo-, pyrimido- and mercaptopyrimidocycloocta[b]indoles
}

Leena Vairavelu', Manonmani Vellingiri² and KJ Rajendra Prasad ${ }^{1 *}$

${ }^{1}$ Department of Chemistry, Bharathiar University, Coimbatore, Tamil Nadu, India

${ }^{2}$ Department of Microbial Biotechnology, Bharathiar University, Coimbatore, Tamil Nadu, India

\begin{abstract}
A new class of heterocycles, (3-7) specifically substituted pyrazolo-, isoxazolo- and pyrimidocycloocta[b]indoles, has been synthesized by condensation of substituted 7-(hydroxymethylene)-5,7,8,9,10,11-hexahydrocycloocta[b] indol-6-ones (2) with hydrazine hydrate, hydroxylamine hydrochloride, phenylhydrazine, urea and thiourea, respectively. The structures of the compounds were established by IR, ${ }^{1} \mathrm{H}$ NMR, ${ }^{13} \mathrm{C}$ NMR and the compounds have been screened for in vitro antibacterial and antitumor activities against two human cancer cell lines (A549 and MCF7). Among the compounds screened, $\mathbf{6 b}$ and $\mathbf{7 b}$ emerged as the most active anti bacterial and the most potent anti proliferative compounds against both the tested cell lines. Structure activity relationship (SAR) analyses confirmed that these two compounds are potential lead for future drug discovery studies.
\end{abstract}

Keywords: 7-(hydroxymethylene)-5,7,8,9,10,11-hexahydrocycloocta $[b]$ indol-6-ones; Claisen condensation; $\mathrm{IC}_{50}$ the cycloocta[b]indole core; Anti tumour activity

\section{Introduction}

The design of molecules that spontaneously organize into helical architecture is of desirable interest [1] because of their fascinating structural features as well as their potential applications. Alkaloids that contain indole units such as prenylated indoles, carbazoles, indolo quinolone, cycloocta[ $b]$ indole have often showed high levels of biological activities such as antiamoebic, antiplasmodic, antiprotozol and antihypertensive activities [2-5]. Among them, cycloocta[b] indole is an emerging class of biologically relevant indole analogue that has been found in many naturally occurring alkaloids such as macroline, ajmaline, macrocarpamine, villalstonine, $\mathrm{O}$-acetyl macralstonine and macralstonine. The cycloocta $[b]$ indole framework has recently been a subject of biology-oriented synthesis (BIOS) [6] and their analogues are promising targets for developing a novel class of potent and selective Mycobacterium protein tyrosine phosphatase B (MptpB) inhibitors against Mycobacterium tuberculosis [7]. The diverse biological activities of these alkaloids (Figure 1) validate the cycloocta $[b]$ indole core as a promising scaffold for the generation of bioactive compounds.

Although several reports are available on the synthesis of functionalized cyclohepta $[b]$ indoles $[8,9]$ and carbazoles, the reports regarding the synthesis and utilization of cycloocta $[b]$ indoles are scant. The reports available in the literature describing the synthetic methods towards Macroline and Sarpagine are problematic which involves multi step preparations of appropriate precursors, harsh reaction or poor region selectivity of the cyclization step. The structural, biological and pharmacological importance of cycloocta $[b]$ indoles, and the lack of reports on their synthesis have prompted us to device a reliable synthetic route to prepare these classes of compounds using different methodologies. Hence this manuscript presents the results of detailed investigations on the synthesis and in vitro evaluation of the antibacterial and antitumor properties of novel annulated cycloocta $[b]$ indoles. To the best of our knowledge and in the open literature, this is the first report on the synthesis and biological evaluation of pyrazolo-, isoxazolo-, and pyrimidocycloocta $[b]$ indoles.

\section{Experimental}

\section{Chemistry}

General procedure for the synthesis of 7-(hydroxymethylene)5,7,8,9,10,11-hexahydro cycloocta $[\boldsymbol{b}]$ indol-6-ones (2): An appropriate 5,7,8,9,10,11-hexahydrocycloocta[b]indol-6-one $(\mathbf{1}, 0.001$ $\mathrm{mol})$, was added in portion over a period of $5 \mathrm{~min}$ to a well cooled vigorously stirred mixture of sodium methoxide ( $2.5 \mathrm{~g}$ of sodium in 25 $\mathrm{mL}$ of methanol) and ethyl formate $(15 \mathrm{~mL})$. The mixture was stirred in ice bath for another half an hour and then allowed to stand at room temperature for $24 \mathrm{~h}$. At the end of the period, ice water was added to the yellow solid mass and acidified with concentrated hydrochloric acid. The precipitate obtained was filtered and dried. The brown solid mass thus separated out was then purified by column chromatography over silica gel using petroleum ether:ethyl acetate (99:1) as eluent to yield the corresponding 7-(hydroxymethylene)-5,7,8,9,10,11hexahydrocycloocta[b]indol-6-one (2).

7 - (Hydroxym et hylene ) - 2 - methyl- $5,7,8,9,10,11$ hexahydrocycloocta $[\boldsymbol{b}]$ indol-6-one (2a): Yellow solid; yield: $90 \%$; m.p. $185-187^{\circ} \mathrm{C}$; IR $\left(\mathrm{KBr}, \mathrm{cm}^{-1}\right) v_{\mathrm{max}}: 3313(\mathrm{~N}-\mathrm{H}), 1625(\mathrm{C}=\mathrm{O}) ;{ }^{1} \mathrm{H} \mathrm{NMR}$ $\left(500 \mathrm{MHz}, \mathrm{CDCl}_{3}\right)(\mathrm{ppm}) \delta_{\mathrm{H}}: 15.62\left(\mathrm{~d}, 1 \mathrm{H}, \mathrm{C}_{7}-\mathrm{CHOH}, J=8.05 \mathrm{~Hz}\right), 8.89$ (b s, $\left.1 \mathrm{H}, \mathrm{N}_{5}-\mathrm{H}\right), 7.90\left(\mathrm{~d}, 1 \mathrm{H}, \mathrm{C}_{7}-\mathrm{CHOH}, J=8.05 \mathrm{~Hz}\right), 7.49-7.19(\mathrm{~m}, 3 \mathrm{H}$, $\mathrm{C}_{1}, \mathrm{C}_{3}$ and $\left.\mathrm{C}_{4}-\mathrm{H}\right), 3.03-2.72\left(\mathrm{~m}, 4 \mathrm{H}, \mathrm{C}_{8}\right.$ and $\left.\mathrm{C}_{11}-\mathrm{H}\right), 2.48\left(\mathrm{~s}, 3 \mathrm{H}, \mathrm{C}_{2}-\mathrm{CH}_{3}\right)$, 1.68-1.49 (m, $4 \mathrm{H}, \mathrm{C}_{9}$ and $\left.\mathrm{C}_{10}-\mathrm{H}\right) ;{ }^{13} \mathrm{C} \mathrm{NMR}\left(125 \mathrm{MHz}, \mathrm{CDCl}_{3}\right)(\mathrm{ppm})$ $\delta_{\mathrm{C}}: 182.0(\mathrm{C}=\mathrm{O}), 163.7\left(\mathrm{C}_{7}-\mathrm{CHO}\right), 142.8\left(\mathrm{C}_{4 \mathrm{a}}\right), 137.8\left(\mathrm{C}_{5 \mathrm{a}}\right), 135.9\left(\mathrm{C}_{11 \mathrm{~b}}\right)$, $131.4\left(\mathrm{C}_{2}\right), 126.9\left(\mathrm{C}_{112}\right), 122.6\left(\mathrm{C}_{1}\right), 120.5\left(\mathrm{C}_{3}\right), 117.0\left(\mathrm{C}_{7}\right), 112.0\left(\mathrm{C}_{4}\right)$, $29.7\left(\mathrm{C}_{10}\right), 27.8\left(\mathrm{C}_{8}\right), 27.2\left(\mathrm{C}_{9}\right), 24.8\left(\mathrm{C}_{11}\right), 21.2\left(\mathrm{C}_{2}-\mathrm{CH}_{3}\right) ; \mathrm{MS}: \mathrm{m} / z\left(\mathrm{M}^{+}\right.$, 255); Anal. calcd. for: $\mathrm{C}_{16} \mathrm{H}_{17} \mathrm{NO}_{2}: \mathrm{C}, 75.27 ; \mathrm{H}, 6.71 ; \mathrm{N}, 5.49$. Found: $\mathrm{C}$, 75.30; H, 6.76; N, 5.54\%.

*Corresponding author: KJ Rajendra Prasad, UGC-Emeritus Professor Department of Chemistry, Bharathiar University, Coimbatore-641 046, Tamil Nadu, India, Tel: +914222422311; E-mail: prasad_125@yahoo.com

Received May 13, 2016; Accepted May 24, 2016; Published May 30, 2016

Citation: Vairavelu L, Vellingiri M, Prasad KJR (2016) Synthesis, Biological Evaluation and Structure Activity Relationship of Substituted pyrazolo-, isoxazolopyrimido- and mercaptopyrimidocycloocta[b]indoles. Med chem (Los Angeles) 6: 356-364. doi:10.4172/2161-0444.1000370

Copyright: @ 2016 Vairavelu L, et al. This is an open-access article distributed under the terms of the Creative Commons Attribution License, which permits unrestricted use, distribution, and reproduction in any medium, provided the original author and source are credited. 

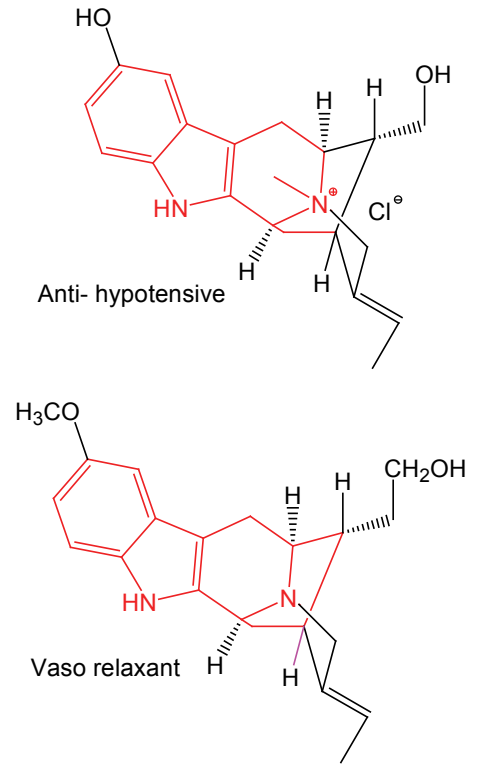
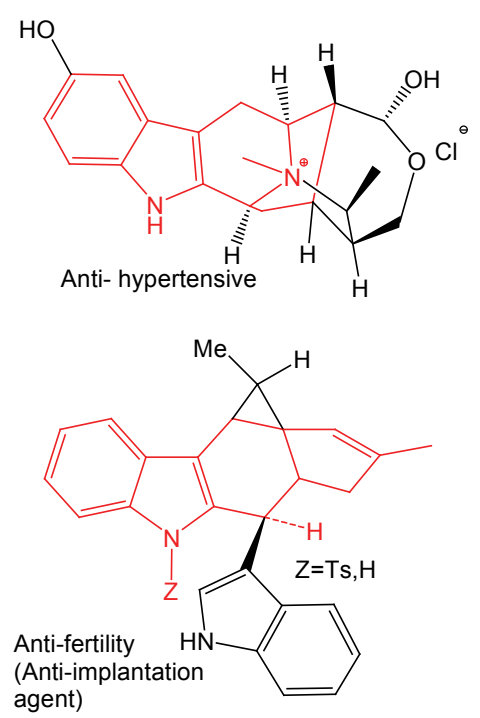

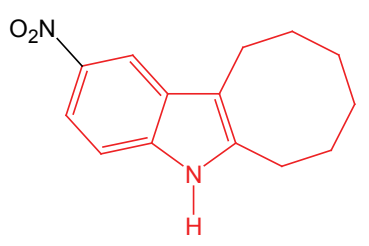

Antidepressant

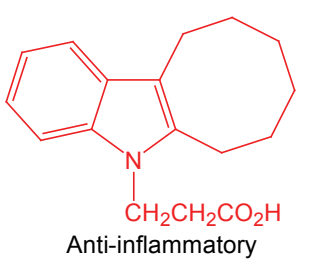

Figure 1: Representative naturally occurring bio active cycloocta[b]indole alkaloids.

2-Chloro- 7 - ( hydroxymethylene ) - $5,7,8,9,10,11$ hexahydrocycloocta $[\boldsymbol{b}]$ indol-6-one (2b): Yellow solid; yield: $82 \%$; m.p. $170-172^{\circ} \mathrm{C}$; IR $\left(\mathrm{KBr}, \mathrm{cm}^{-1}\right) v_{\max }: 3353(\mathrm{~N}-\mathrm{H}), 1619(\mathrm{C}=\mathrm{O}) ;{ }^{1} \mathrm{H}$ NMR $\left(500 \mathrm{MHz}, \mathrm{CDCl}_{3}\right)(\mathrm{ppm}) \delta_{\mathrm{H}}: 15.47\left(\mathrm{~d}, 1 \mathrm{H}, \mathrm{C}_{7}-\mathrm{CHOH}, J=8.50 \mathrm{~Hz}\right), 8.78$ (b s, $\left.1 \mathrm{H}, \mathrm{N}_{5}-\mathrm{H}\right), 7.60\left(\mathrm{~d}, 1 \mathrm{H}, \mathrm{C}_{7}-\mathrm{CHOH}, J=8.50 \mathrm{~Hz}\right), 7.36-7.20(\mathrm{~m}, 3 \mathrm{H}$, $\mathrm{C}_{1}, \mathrm{C}_{3}$ and $\left.\mathrm{C}_{4}-\mathrm{H}\right), 2.98-1.40\left(\mathrm{~m}, 8 \mathrm{H}, \mathrm{C}_{8}, \mathrm{C}_{9}, \mathrm{C}_{10}\right.$ and $\left.\mathrm{C}_{11}-\mathrm{H}\right) ;{ }^{13} \mathrm{C}$ NMR $\left(125 \mathrm{MHz}, \mathrm{CDCl}_{3}\right)(\mathrm{ppm}) \delta_{\mathrm{C}}: 180.0(\mathrm{C}=\mathrm{O}), 166.7\left(\mathrm{C}_{7}-\mathrm{CHO}\right), 141.8$ $\left(\mathrm{C}_{4 \mathrm{a}}\right), 138.6\left(\mathrm{C}_{5 \mathrm{a}}\right), 137.8\left(\mathrm{C}_{11 \mathrm{~b}}\right), 129.5\left(\mathrm{C}_{2}\right), 127.7\left(\mathrm{C}_{11 \mathrm{a}}\right), 123.3\left(\mathrm{C}_{1}\right), 122.2$ $\left(\mathrm{C}_{3}\right), 118.1\left(\mathrm{C}_{7}\right), 113.5\left(\mathrm{C}_{4}\right), 30.0\left(\mathrm{C}_{10}\right), 28.1\left(\mathrm{C}_{8}\right), 26.8\left(\mathrm{C}_{9}\right), 25.2\left(\mathrm{C}_{11}\right)$; MS: $m / z\left(\mathrm{M}^{+}, 275\right)$; Anal. calcd. for: $\mathrm{C}_{15} \mathrm{H}_{14} \mathrm{ClNO}_{2}: \mathrm{C}, 65.34 ; \mathrm{H}, 5.12 ; \mathrm{N}$, 5.08. Found: C, 65.39; H, 5.16; N, 5.04\%.

7 - (Hydroxymethylene ) - 4 - methyl- $5,7,8,9,10,11$ hexahydrocycloocta $[\boldsymbol{b}]$ indol-6-one (2c): Yellow solid; yield: $80 \%$; m.p. $150-152^{\circ} \mathrm{C}$; IR $\left(\mathrm{KBr}, \mathrm{cm}^{-1}\right) v_{\max }: 3345(\mathrm{~N}-\mathrm{H}), 1614(\mathrm{C}=\mathrm{O}) ;{ }^{1} \mathrm{H}$ NMR $\left(500 \mathrm{MHz}, \mathrm{CDCl}_{3}\right)(\mathrm{ppm}) \delta_{\mathrm{H}}: 15.59\left(\mathrm{~d}, 1 \mathrm{H}, \mathrm{C}_{7}-\mathrm{CHOH}, J=8.00 \mathrm{~Hz}\right), 8.79$ (b s, $\left.1 \mathrm{H}, \mathrm{N}_{5}-\mathrm{H}\right), 7.75\left(\mathrm{~d}, 1 \mathrm{H}, \mathrm{C}_{7}-\mathrm{CHOH}, J=8.00 \mathrm{~Hz}\right), 7.48-7.19(\mathrm{~m}, 3 \mathrm{H}$, $\mathrm{C}_{1}, \mathrm{C}_{2}$ and $\left.\mathrm{C}_{3}-\mathrm{H}\right), 3.10-2.87\left(\mathrm{~m}, 4 \mathrm{H}, \mathrm{C}_{8}\right.$ and $\left.\mathrm{C}_{11}-\mathrm{H}\right), 2.50\left(\mathrm{~s}, 3 \mathrm{H}, \mathrm{C}_{4}-\mathrm{CH}_{3}\right)$, 1.78-1.69 (m, 4H, $\mathrm{C}_{9}$ and $\left.\mathrm{C}_{10}-\mathrm{H}\right) ;{ }^{13} \mathrm{C} \mathrm{NMR}\left(125 \mathrm{MHz}, \mathrm{CDCl}_{3}\right)(\mathrm{ppm})$ $\delta_{\mathrm{C}}: 179.7(\mathrm{C}=\mathrm{O}), 164.6\left(\mathrm{C}_{7}-\mathrm{CHO}\right), 143.7\left(\mathrm{C}_{4 \mathrm{a}}\right), 136.9\left(\mathrm{C}_{5 \mathrm{a}}\right), 134.7\left(\mathrm{C}_{11 \mathrm{~b}}\right)$, $128.7\left(\mathrm{C}_{11 \mathrm{a}}\right), 123.4\left(\mathrm{C}_{2}\right), 122.5\left(\mathrm{C}_{3}\right), 121.0\left(\mathrm{C}_{4}\right), 118.6\left(\mathrm{C}_{1}\right), 116.1\left(\mathrm{C}_{7}\right)$, $28.6\left(\mathrm{C}_{10}\right), 27.2\left(\mathrm{C}_{8}\right), 26.7\left(\mathrm{C}_{9}\right), 25.3\left(\mathrm{C}_{11}\right), 17.0\left(\mathrm{C}_{4}-\mathrm{CH}_{3}\right)$; MS: $\mathrm{m} / z\left(\mathrm{M}^{+}\right.$, 255); Anal. calcd. for: $\mathrm{C}_{16} \mathrm{H}_{17} \mathrm{NO}_{2}: \mathrm{C}, 75.27 ; \mathrm{H}, 6.71 ; \mathrm{N}, 5.49$. Found: $\mathrm{C}$, $75.30 ; \mathrm{H}, 6.76 ; \mathrm{N}, 5.54 \%$.

7-(Hydroxymethylene)-5,7,8,9,10,11-hexahydrocycloocta $[b]$ indol-6-one (2d): Yellow solid; yield: 79\%; m.p.161-163 ${ }^{\circ} \mathrm{C}$; IR $(\mathrm{KBr}$, $\left.\mathrm{cm}^{-1}\right) v_{\max }: 3372(\mathrm{~N}-\mathrm{H}), 1610(\mathrm{C}=\mathrm{O}) ;{ }^{1} \mathrm{H}$ NMR $\left(500 \mathrm{MHz}, \mathrm{CDCl}_{3}\right)$ $(\mathrm{ppm}) \delta_{\mathrm{H}}: 15.58\left(\mathrm{~d}, 1 \mathrm{H}, \mathrm{C}_{7}-\mathrm{CHOH}, J=8.00 \mathrm{~Hz}\right), 8.94\left(\mathrm{~b} \mathrm{~s}, 1 \mathrm{H}, \mathrm{N}_{5}-\mathrm{H}\right)$, $7.58\left(\mathrm{~d}, 1 \mathrm{H}, \mathrm{C}_{7}-\mathrm{CHOH}, \mathrm{J}=8.00 \mathrm{~Hz}\right), 7.37-7.20\left(\mathrm{~m}, 4 \mathrm{H}, \mathrm{C}_{1}, \mathrm{C}_{2}, \mathrm{C}_{3}\right.$ and $\left.\mathrm{C}_{4}-\mathrm{H}\right)$, 3.05-1.40 (m, 8H, $\mathrm{C}_{8}, \mathrm{C}_{9}, \mathrm{C}_{10}$ and $\left.\mathrm{C}_{11}-\mathrm{H}\right) ;{ }^{13} \mathrm{C} \mathrm{NMR}(125 \mathrm{MHz}$, $\left.\mathrm{CDCl}_{3}\right)(\mathrm{ppm}) \delta_{\mathrm{C}}: 176.8(\mathrm{C}=\mathrm{O}), 165.4\left(\mathrm{C}_{7}-\mathrm{CHO}\right), 144.2\left(\mathrm{C}_{4 \mathrm{a}}\right), 139.0$ $\left(\mathrm{C}_{5 \mathrm{a}}\right), 135.1\left(\mathrm{C}_{11 \mathrm{~b}}\right), 128.0\left(\mathrm{C}_{11 \mathrm{a}}\right), 122.5\left(\mathrm{C}_{2}\right), 121.7\left(\mathrm{C}_{1}\right), 120.2\left(\mathrm{C}_{3}\right), 117.7$ $\left(\mathrm{C}_{7}\right), 112.6\left(\mathrm{C}_{4}\right), 29.3\left(\mathrm{C}_{10}\right), 28.7\left(\mathrm{C}_{8}\right), 27.0\left(\mathrm{C}_{9}\right), 26.2\left(\mathrm{C}_{11}\right)$; MS: $\mathrm{m} / z\left(\mathrm{M}^{+}\right.$, 241); Anal. calcd. for: $\mathrm{C}_{15} \mathrm{H}_{15} \mathrm{NO}_{2}: \mathrm{C}, 74.67 ; \mathrm{H}, 6.27 ; \mathrm{N}, 5.81$. Found: $\mathrm{C}$, $74.74 ; \mathrm{H}, 6.21 ; \mathrm{N}, 5.84 \%$.

General procedureforthesynthesisof 4,5,6,7,-tetrahydropyrazolo $\left[3^{\prime}, 4^{\prime}: 8,7\right]-12 H$-cycloocta $[b]$ indoles (3): The reaction mixture consisting of the appropriate 7-(hydroxymethylene)-5,7,8,9,10,11hexahydrocycloocta[b]indol-6-one $(2,0.001 \mathrm{~mol})$, hydrazine hydrate $(0.5 \mathrm{~mL})$ was refluxed in absolute ethanol $(15 \mathrm{~mL})$ for $5 \mathrm{~h}$. After the completion of the reaction, the excess solvent was removed by distillation and the mixture was poured into ice-water, filtered, dried and purified by column chromatography (eluent: petroleum ether:ethyl acetate, 85:15) and recrystallized from ethanol to give the respective 4,5,6,7-tetrahydropyrazolo[ $\left[3^{\prime}, 4^{\prime}: 8,7\right]-12 H$-cycloocta[ $\left.b\right]$ indole (3) as yellow prism.

9-Methyl-4, 5, 6, 7-tetrahydropyrazolo [ $\left.3^{\prime}, 4^{\prime}: 8,7\right]-12 \mathrm{H}$ cycloocta $[\boldsymbol{b}]$ indole $(3 \mathrm{a})$ : Yellow prism; yield: $68 \%$; m.p.210-212 ${ }^{\circ} \mathrm{C}$; IR $\left(\mathrm{KBr}, \mathrm{cm}^{-1}\right) v_{\text {max }}: 3394(\mathrm{~N}-\mathrm{H}), 1600(\mathrm{C}=\mathrm{N}) ;{ }^{1} \mathrm{H}$ NMR $\left(500 \mathrm{MHz}, \mathrm{CDCl}_{3}\right)$ (ppm) $\delta_{\mathrm{H}}: 9.01\left(\mathrm{~b} \mathrm{~s}, 1 \mathrm{H}, \mathrm{N}_{12}-\mathrm{H}\right), 7.57\left(\mathrm{~s}, 1 \mathrm{H}, \mathrm{N}_{2}-\mathrm{H}\right), 7.48-7.20(\mathrm{~m}, 4 \mathrm{H}$, $\mathrm{C}_{3}, \mathrm{C}_{8}, \mathrm{C}_{10}$ and $\left.\mathrm{C}_{11}-\mathrm{H}\right), 3.07-2.69\left(\mathrm{~m}, 4 \mathrm{H}, \mathrm{C}_{4}\right.$ and $\left.\mathrm{C}_{7}-\mathrm{H}\right), 2.52(\mathrm{~s}, 3 \mathrm{H}$, $\left.\mathrm{C}_{9}-\mathrm{CH}_{3}\right), 1.94-1.78\left(\mathrm{~m}, 4 \mathrm{H}, \mathrm{C}_{5}\right.$ and $\left.\mathrm{C}_{6}-\mathrm{H}\right) ;{ }^{13} \mathrm{C}$ NMR $\left(125 \mathrm{MHz}, \mathrm{CDCl}_{3}\right)$ $(\mathrm{ppm}) \delta_{\mathrm{C}}: 134.5\left(\mathrm{C}_{11 \mathrm{a}}\right), 131.8\left(\mathrm{C}_{3}\right), 129.0\left(\mathrm{C}_{12 \mathrm{~b}}\right), 128.2\left(\mathrm{C}_{9}\right), 126.8\left(\mathrm{C}_{12 \mathrm{a}}\right)$, $125.9\left(\mathrm{C}_{7 \mathrm{~b}}\right), 121.0\left(\mathrm{C}_{8}\right), 120.2\left(\mathrm{C}_{10}\right), 114.5\left(\mathrm{C}_{3 \mathrm{a}}\right), 113.1\left(\mathrm{C}_{7 \mathrm{a}}\right), 110.2\left(\mathrm{C}_{11}\right)$, $29.0\left(\mathrm{C}_{6}\right), 27.2\left(\mathrm{C}_{5}\right), 25.1\left(\mathrm{C}_{7}\right), 23.1\left(\mathrm{C}_{4}\right), 21.1\left(\mathrm{C}_{9}-\mathrm{CH}_{3}\right) ; \mathrm{MS}: \mathrm{m} / z\left(\mathrm{M}^{+}\right.$, 251); Anal. calcd. For: $\mathrm{C}_{16} \mathrm{H}_{17} \mathrm{~N}_{3}: \mathrm{C}, 76.46 ; \mathrm{H}, 6.82 ; \mathrm{N}, 16.72$. Found: $\mathrm{C}$, $76.50 ; \mathrm{H}, 6.77 ; \mathrm{N}, 16.80 \%$.

9-Chloro-4, 5, 6,7-tetrahydropyrazolo [ $\left.3^{\prime}, 44^{\prime}: 8,7\right]-12 \mathrm{H}$ cycloocta $[\boldsymbol{b}]$ indole $(3 \mathbf{b})$ : Yellow prism; yield: $62 \%$; m.p.220-222 ${ }^{\circ} \mathrm{C}$; IR $\left(\mathrm{KBr}, \mathrm{cm}^{-1}\right) v_{\max }: 3332(\mathrm{~N}-\mathrm{H}), 1614(\mathrm{C}=\mathrm{N}) ;{ }^{1} \mathrm{H} \mathrm{NMR}\left(500 \mathrm{MHz}, \mathrm{CDCl}_{3}\right)$ (ppm) $\delta_{\mathrm{H}}: 9.31\left(\mathrm{~b} \mathrm{~s}, 1 \mathrm{H}, \mathrm{N}_{12}-\mathrm{H}\right), 7.45\left(\mathrm{~s}, 1 \mathrm{H}, \mathrm{N}_{2}-\mathrm{H}\right), 7.33-7.00(\mathrm{~m}, 4 \mathrm{H}$, $\mathrm{C}_{3}, \mathrm{C}_{8}, \mathrm{C}_{10}$ and $\left.\mathrm{C}_{11}-\mathrm{H}\right), 2.92-1.50\left(\mathrm{~m}, 8 \mathrm{H}, \mathrm{C}_{4}, \mathrm{C}_{5}, \mathrm{C}_{6}\right.$ and $\left.\mathrm{C}_{7}-\mathrm{H}\right) ;{ }^{13} \mathrm{C}$ NMR $\left(125 \mathrm{MHz}, \mathrm{CDCl}_{3}\right)(\mathrm{ppm}) \delta_{\mathrm{C}}: 135.7\left(\mathrm{C}_{11 \mathrm{a}}\right), 131.8\left(\mathrm{C}_{3}\right), 130.0\left(\mathrm{C}_{12 \mathrm{~b}}\right), 127.9$ $\left(\mathrm{C}_{9}\right), 125.0\left(\mathrm{C}_{12 \mathrm{a}}\right), 124.1\left(\mathrm{C}_{7 \mathrm{~b}}\right), 122.3\left(\mathrm{C}_{8}\right), 121.7\left(\mathrm{C}_{10}\right), 115.3\left(\mathrm{C}_{3 \mathrm{a}}\right), 114.0$ $\left(\mathrm{C}_{7 \mathrm{a}}\right), 111.8\left(\mathrm{C}_{11}\right), 29.1\left(\mathrm{C}_{6}\right), 27.9\left(\mathrm{C}_{5}\right), 26.8\left(\mathrm{C}_{7}\right), 25.5\left(\mathrm{C}_{4}\right) ; \mathrm{MS}: \mathrm{m} / z\left(\mathrm{M}^{+}\right.$, 271); Anal. calcd. for: $\mathrm{C}_{15} \mathrm{H}_{14} \mathrm{~N}_{3}: \mathrm{C}, 66.30 ; \mathrm{H}, 5.19 ; \mathrm{N}, 15.46$. Found: $\mathrm{C}$, $66.35 ; \mathrm{H}, 5.17 ; \mathrm{N}, 15.50 \%$.

11 - Methyl-4,5,6,7-tetrahydropyrazolo $\left[3^{\prime}, 4^{\prime}: 8,7\right]-12 H$ cycloocta $[\boldsymbol{b}]$ indole $(3 \mathrm{c})$ : Yellow prism; yield: $66 \%$; m.p. $191-193^{\circ} \mathrm{C}$; IR $\left(\mathrm{KBr}, \mathrm{cm}^{-1}\right) v_{\max }: 3367(\mathrm{~N}-\mathrm{H}), 1602(\mathrm{C}=\mathrm{N}) ;{ }^{1} \mathrm{H}$ NMR $\left(500 \mathrm{MHz}, \mathrm{CDCl}_{3}\right)$ (ppm) $\delta_{\mathrm{H}}: 9.21\left(\mathrm{~b} \mathrm{~s}, 1 \mathrm{H}, \mathrm{N}_{12}-\mathrm{H}\right), 7.59\left(\mathrm{~s}, 1 \mathrm{H}, \mathrm{N}_{2}-\mathrm{H}\right), 7.50-7.08(\mathrm{~m}, 4 \mathrm{H}$, $\mathrm{C}_{3}, \mathrm{C}_{8}, \mathrm{C}_{9}$ and $\left.\mathrm{C}_{10}-\mathrm{H}\right), 3.17-2.88\left(\mathrm{~m}, 4 \mathrm{H}, \mathrm{C}_{4}\right.$ and $\left.\mathrm{C}_{7}-\mathrm{H}\right), 2.61\left(\mathrm{~s}, 3 \mathrm{H}, \mathrm{C}_{11}-\right.$ $\left.\mathrm{CH}_{3}\right), 2.12-1.98\left(\mathrm{~m}, 4 \mathrm{H}, \mathrm{C}_{5}\right.$ and $\left.\mathrm{C}_{6}-\mathrm{H}\right) ;{ }^{13} \mathrm{C}$ NMR $\left(125 \mathrm{MHz}, \mathrm{CDCl}_{3}\right)$ 
Citation: Vairavelu L, Vellingiri M, Prasad KJR (2016) Synthesis, Biological Evaluation and Structure Activity Relationship of Substituted pyrazolo-, isoxazolo-, pyrimido- and mercaptopyrimidocycloocta[b]indoles. Med chem (Los Angeles) 6: 356-364. doi:10.4172/2161-0444.1000370

$(\mathrm{ppm}) \delta_{\mathrm{C}}: 136.7\left(\mathrm{C}_{11 \mathrm{a}}\right), 132.5\left(\mathrm{C}_{3}\right), 131.6\left(\mathrm{C}_{12 \mathrm{~b}}\right), 127.5\left(\mathrm{C}_{12 \mathrm{a}}\right), 126.3$ $\left(\mathrm{C}_{7 \mathrm{~b}}\right), 124.0\left(\mathrm{C}_{9}\right), 121.0\left(\mathrm{C}_{10}\right), 120.5\left(\mathrm{C}_{11}\right), 119.2\left(\mathrm{C}_{9}\right), 116.7\left(\mathrm{C}_{3 \mathrm{a}}\right), 114.1$ $\left(\mathrm{C}_{7 \mathrm{a}}\right), 28.4\left(\mathrm{C}_{6}\right), 26.8\left(\mathrm{C}_{5}\right), 25.7\left(\mathrm{C}_{7}\right), 24.0\left(\mathrm{C}_{4}\right), 18.9\left(\mathrm{C}_{11}-\mathrm{CH}_{3}\right) ; \mathrm{MS}: \mathrm{m} / z$ $\left(\mathrm{M}^{+}, 251\right)$; Anal. calcd. for: $\mathrm{C}_{16} \mathrm{H}_{17} \mathrm{~N}_{3}: \mathrm{C}, 76.46 ; \mathrm{H}, 6.82 ; \mathrm{N}, 16.72$. Found: C, $76.50 ; \mathrm{H}, 6.77 ; \mathrm{N}, 16.80 \%$.

4,5,6,7-Tetrahydropyrazolo $\left[3^{\prime}, 4^{\prime}: 8,7\right]-12 H-\quad$ cycloocta $[b]$ indole (3d): Yellow prism; yield: 64\%; m.p. $197-199^{\circ} \mathrm{C}$; IR $\left(\mathrm{KBr}, \mathrm{cm}^{-1}\right) \nu_{\max }: 3329$ $(\mathrm{N}-\mathrm{H}), 1607(\mathrm{C}=\mathrm{N}) ;{ }^{1} \mathrm{H}$ NMR $\left(500 \mathrm{MHz}, \mathrm{CDCl}_{3}\right)(\mathrm{ppm}) \delta_{\mathrm{H}}: 8.98(\mathrm{~b} \mathrm{~s}$, $\left.1 \mathrm{H}, \mathrm{N}_{12}-\mathrm{H}\right), 7.69\left(\mathrm{~s}, 1 \mathrm{H}, \mathrm{N}_{2}-\mathrm{H}\right), 7.41-7.06\left(\mathrm{~m}, 5 \mathrm{H}, \mathrm{C}_{3}, \mathrm{C}_{8}, \mathrm{C}_{9}, \mathrm{C}_{10}\right.$ and $\left.\mathrm{C}_{11}-\mathrm{H}\right), 3.01-2.10\left(\mathrm{~m}, 8 \mathrm{H}, \mathrm{C}_{4}, \mathrm{C}_{5}, \mathrm{C}_{6}\right.$ and $\left.\mathrm{C}_{7}-\mathrm{H}\right) ;{ }^{13} \mathrm{C}$ NMR $(125 \mathrm{MHz}$, $\left.\mathrm{CDCl}_{3}\right)(\mathrm{ppm}) \delta_{\mathrm{C}}: 137.5\left(\mathrm{C}_{11 \mathrm{a}}\right), 132.9\left(\mathrm{C}_{3}\right), 131.4\left(\mathrm{C}_{12 \mathrm{~b}}\right), 126.1\left(\mathrm{C}_{7 \mathrm{~b}}\right)$, $125.6\left(\mathrm{C}_{12 \mathrm{a}}\right), 123.9\left(\mathrm{C}_{9}\right), 122.6\left(\mathrm{C}_{8}\right), 121.0\left(\mathrm{C}_{10}\right), 114.9\left(\mathrm{C}_{3 \mathrm{a}}\right), 113.4\left(\mathrm{C}_{7 \mathrm{a}}\right)$, $112.6\left(\mathrm{C}_{11}\right), 28.8\left(\mathrm{C}_{6}\right), 27.2\left(\mathrm{C}_{5}\right), 25.7\left(\mathrm{C}_{7}\right), 24.6\left(\mathrm{C}_{4}\right) ; \mathrm{MS}: \mathrm{m} / z\left(\mathrm{M}^{+}, 237\right)$; Anal. calcd. for: $\mathrm{C}_{15} \mathrm{H}_{15} \mathrm{~N}_{3}$ : C, 75.92; $\mathrm{H}, 6.37 ; \mathrm{N}, 17.71$. Found: $\mathrm{C}, 75.97$; $\mathrm{H}, 6.31 ; \mathrm{N}, 17.66 \%$.

Generalprocedureforthesynthesisof 4,5,6,7-tetrahydroisoxazolo $\left[3^{\prime}, 4^{\prime}: 8,7\right]-12 H$-cycloocta $[b]$ indoles (4): The reaction mixture consisting of the appropriate 7-(hydroxymethylene)-5,7,8,9,10,11hexahydrocycloocta[b]indol-6-one $(2,0.001 \mathrm{~mol})$, hydroxylamine hydrochloride $(0.34 \mathrm{~g})$ and glacial acetic acid $(5 \mathrm{~mL})$ was refluxed at $120^{\circ} \mathrm{C}$ for $4 \mathrm{~h}$. After the completion of the reaction, it was cooled and poured into crushed ice, the solid thus separated out was filtered, washed with water, dried and purified by column chromatography (eluent: petroleum ether:ethyl acetate, 85:15) and recrystallized from ethanol to give the respective 4,5,6,7-tetrahydroisoxazolo[3',4':8,7]$12 \mathrm{H}$-cycloocta[ $b]$ indole (4).

9-Methyl-4,5,6,7-tetrahydroisoxazolo $\left[3^{\prime}, 4^{\prime}: 8,7\right]-12 H$ cycloocta $[\boldsymbol{b}]$ indole $(4 \mathrm{a})$ : Yellow prism; yield: $63 \%$; m.p.210-212 ${ }^{\circ} \mathrm{C}$; IR $\left(\mathrm{KBr}, \mathrm{cm}^{-1}\right) v_{\max }: 3426(\mathrm{~N}-\mathrm{H}), 1611(\mathrm{C}=\mathrm{N}) ;{ }^{1} \mathrm{H}$ NMR $(500 \mathrm{MHz}$, $\left.\mathrm{CDCl}_{3}\right)(\mathrm{ppm}) \delta_{\mathrm{H}}: 8.93\left(\mathrm{~b} \mathrm{~s}, 1 \mathrm{H}, \mathrm{N}_{12}-\mathrm{H}\right), 8.19-7.09\left(\mathrm{~m}, 4 \mathrm{H}, \mathrm{C}_{3}, \mathrm{C}_{8}, \mathrm{C}_{10}\right.$ and $\left.\mathrm{C}_{11}-\mathrm{H}\right), 3.08-2.67\left(\mathrm{~m}, 4 \mathrm{H}, \mathrm{C}_{4}\right.$ and $\left.\mathrm{C}_{7}-\mathrm{H}\right), 2.41\left(\mathrm{~s}, 3 \mathrm{H}, \mathrm{C}_{9}-\mathrm{CH}_{3}\right)$, 1.70-1.49 (m, 4H, $\mathrm{C}_{5}$ and $\left.\mathrm{C}_{6}-\mathrm{H}\right) ;{ }^{13} \mathrm{C} \mathrm{NMR}\left(125 \mathrm{MHz}, \mathrm{CDCl}_{3}\right)(\mathrm{ppm}) \delta_{\mathrm{C}}$ : $159.7\left(\mathrm{C}_{12 \mathrm{~b}}\right), 151.8\left(\mathrm{C}_{3}\right), 132.2\left(\mathrm{C}_{11 \mathrm{a}}\right), 128.7\left(\mathrm{C}_{9}\right), 127.4\left(\mathrm{C}_{7 \mathrm{~b}}\right), 126.1\left(\mathrm{C}_{12 \mathrm{a}}\right)$, $123.4\left(\mathrm{C}_{8}\right), 120.7\left(\mathrm{C}_{10}\right), 115.5\left(\mathrm{C}_{7 \mathrm{a}}\right), 113.7\left(\mathrm{C}_{3 \mathrm{a}}\right), 111.5\left(\mathrm{C}_{11}\right), 27.8\left(\mathrm{C}_{6}\right)$, $26.7\left(\mathrm{C}_{5}\right), 24.7\left(\mathrm{C}_{7}\right), 24.0\left(\mathrm{C}_{4}\right), 21.2\left(\mathrm{C}_{9}-\mathrm{CH}_{3}\right) ; \mathrm{MS}: \mathrm{m} / z\left(\mathrm{M}^{+}, 252\right)$; Anal. calcd. for: $\mathrm{C}_{16} \mathrm{H}_{16} \mathrm{~N}_{2} \mathrm{O}: \mathrm{C}, 76.16 ; \mathrm{H}, 6.39 ; \mathrm{N}, 11.10$. Found: $\mathrm{C}, 76.20 ; \mathrm{H}$, $6.34 ; \mathrm{N}, 11.04 \%$.

9-Chloro-4,5,6,7-tetrahyd roisoxazolo [ $\left.3^{\prime}, 4^{\prime}: 8,7\right]-12 H$ cycloocta $[\boldsymbol{b}]$ indole $(4 \mathbf{b})$ : Yellow prism; yield: $58 \%$; m.p.204-206 ${ }^{\circ} \mathrm{C}$; IR $\left(\mathrm{KBr}, \mathrm{cm}^{-1}\right) v_{\max }: 3414(\mathrm{~N}-\mathrm{H}), 1617(\mathrm{C}=\mathrm{N}) ;{ }^{1} \mathrm{H}$ NMR $\left(500 \mathrm{MHz}, \mathrm{CDCl}_{3}\right)$ $(\mathrm{ppm}) \delta_{\mathrm{H}}: 8.78\left(\mathrm{~b} \mathrm{~s}, 1 \mathrm{H}, \mathrm{N}_{12}-\mathrm{H}\right), 8.09-7.08\left(\mathrm{~m}, 4 \mathrm{H}, \mathrm{C}_{3}, \mathrm{C}_{8}, \mathrm{C}_{10}\right.$ and $\left.\mathrm{C}_{11}-\mathrm{H}\right)$, 3.01-1.60 (m, 8H, $\mathrm{C}_{4}, \mathrm{C}_{5}, \mathrm{C}_{6}$ and $\left.\left.\mathrm{C}_{7}-\mathrm{H}\right) ;{ }^{13} \mathrm{C} \mathrm{NMR} \mathrm{(125} \mathrm{MHz,} \mathrm{CDCl}_{3}\right)$ $(\mathrm{ppm}) \delta_{\mathrm{C}}: 157.4\left(\mathrm{C}_{12 \mathrm{~b}}\right), 150.6\left(\mathrm{C}_{3}\right), 134.1\left(\mathrm{C}_{11 \mathrm{a}}\right), 129.2\left(\mathrm{C}_{7 \mathrm{~b}}\right), 128.0\left(\mathrm{C}_{9}\right)$, $125.2\left(\mathrm{C}_{12 \mathrm{a}}\right), 122.3\left(\mathrm{C}_{8}\right), 121.5\left(\mathrm{C}_{10}\right), 114.1\left(\mathrm{C}_{7 \mathrm{a}}\right), 112.6\left(\mathrm{C}_{3 \mathrm{a}}\right), 111.0\left(\mathrm{C}_{11}\right)$, $28.9\left(\mathrm{C}_{6}\right), 27.2\left(\mathrm{C}_{5}\right), 25.6\left(\mathrm{C}_{7}\right), 24.5\left(\mathrm{C}_{4}\right)$; MS: $m / z\left(\mathrm{M}^{+}, 272\right)$; Anal. calcd. for: $\mathrm{C}_{15} \mathrm{H}_{13} \mathrm{ClN}_{2} \mathrm{O}: \mathrm{C}, 66.06 ; \mathrm{H}, 4.80 ; \mathrm{N}, 10.07$. Found: $\mathrm{C}, 66.10 ; \mathrm{H}, 4.75$; $\mathrm{N}, 10.12 \%$.

11 -Methyl-4,5,6,7-tetrahydroisoxazolo [ $\left.3^{\prime}, 4^{\prime}: 8,7\right]-12 \mathrm{H}$ cycloocta $[\boldsymbol{b}]$ indole $(4 \mathrm{c})$ : Yellow prism; yield: $56 \%$; m.p.219-221 ${ }^{\circ} \mathrm{C}$; IR $\left(\mathrm{KBr}, \mathrm{cm}^{-1}\right) v_{\max }: 3435(\mathrm{~N}-\mathrm{H}), 1619(\mathrm{C}=\mathrm{N}) ;{ }^{1} \mathrm{H}$ NMR $\left(500 \mathrm{MHz}, \mathrm{CDCl}_{3}\right)$ $(\mathrm{ppm}) \delta_{\mathrm{H}}: 8.96\left(\mathrm{~b} \mathrm{~s}, 1 \mathrm{H}, \mathrm{N}_{12}-\mathrm{H}\right), 8.03-7.10\left(\mathrm{~m}, 4 \mathrm{H}, \mathrm{C}_{3}, \mathrm{C}_{8}, \mathrm{C}_{9}\right.$ and $\left.\mathrm{C}_{10}-\mathrm{H}\right)$, 3.10-2.92 (m, $4 \mathrm{H}, \mathrm{C}_{4}$ and $\left.\mathrm{C}_{7}-\mathrm{H}\right), 2.43\left(\mathrm{~s}, 3 \mathrm{H}, \mathrm{C}_{11}-\mathrm{CH}_{3}\right), 1.81-1.74(\mathrm{~m}$, $4 \mathrm{H}, \mathrm{C}_{5}$ and $\left.\mathrm{C}_{6}-\mathrm{H}\right) ;{ }^{13} \mathrm{C}$ NMR $\left(125 \mathrm{MHz}, \mathrm{CDCl}_{3}\right)(\mathrm{ppm}) \delta_{\mathrm{C}}: 160.0\left(\mathrm{C}_{12 \mathrm{~b}}\right)$, $152.2\left(\mathrm{C}_{3}\right), 134.1\left(\mathrm{C}_{112}\right), 129.9\left(\mathrm{C}_{7 \mathrm{~b}}\right), 127.5\left(\mathrm{C}_{12 \mathrm{a}}\right), 124.2\left(\mathrm{C}_{9}\right), 122.0\left(\mathrm{C}_{10}\right)$, $121.2\left(\mathrm{C}_{11}\right), 118.8\left(\mathrm{C}_{8}\right), 114.2\left(\mathrm{C}_{7 \mathrm{a}}\right), 112.6\left(\mathrm{C}_{3 \mathrm{a}}\right), 27.9\left(\mathrm{C}_{6}\right), 26.8\left(\mathrm{C}_{5}\right), 24.9$ $\left(\mathrm{C}_{7}\right), 23.8\left(\mathrm{C}_{4}\right), 19.0\left(\mathrm{C}_{11}-\mathrm{CH}_{3}\right)$; MS: $m / z\left(\mathrm{M}^{+}, 252\right)$; Anal. calcd. for: $\mathrm{C}_{16} \mathrm{H}_{16} \mathrm{~N}_{2} \mathrm{O}: \mathrm{C}, 76.16 ; \mathrm{H}, 6.39 ; \mathrm{N}, 11.10$. Found: $\mathrm{C}, 76.20 ; \mathrm{H}, 6.34 ; \mathrm{N}$, $11.04 \%$.
4,5,6,7-Tetrahydroisoxazolo $\left[3^{\prime}, 4^{\prime}: 8,7\right]-12 H$-cycloocta $[b]$ indole (4d): Yellow prism; yield: 55\%; m.p. $197-199^{\circ} \mathrm{C}$; IR $\left(\mathrm{KBr}, \mathrm{cm}^{-1}\right) v_{\max }: 3429$ $(\mathrm{N}-\mathrm{H}), 1613(\mathrm{C}=\mathrm{N}) ;{ }^{1} \mathrm{H}$ NMR $\left(500 \mathrm{MHz}, \mathrm{CDCl}_{3}\right)(\mathrm{ppm}) \delta_{\mathrm{H}}: 9.01(\mathrm{~b} \mathrm{~s}$, $\left.1 \mathrm{H}, \mathrm{N}_{12}-\mathrm{H}\right), 8.22-7.18\left(\mathrm{~m}, 5 \mathrm{H}, \mathrm{C}_{3}, \mathrm{C}_{8}, \mathrm{C}_{9}, \mathrm{C}_{10}\right.$ and $\left.\mathrm{C}_{11}-\mathrm{H}\right), 3.04-1.67(\mathrm{~m}$, $8 \mathrm{H}, \mathrm{C}_{4}, \mathrm{C}_{5}, \mathrm{C}_{6}$ and $\left.\mathrm{C}_{7}-\mathrm{H}\right) ;{ }^{13} \mathrm{C} \mathrm{NMR}\left(125 \mathrm{MHz}, \mathrm{CDCl}_{3}\right)(\mathrm{ppm}) \delta_{\mathrm{C}}: 158.1$ $\left(\mathrm{C}_{12 \mathrm{~b}}\right), 151.3\left(\mathrm{C}_{3}\right), 135.4\left(\mathrm{C}_{11 \mathrm{a}}\right), 130.3\left(\mathrm{C}_{7 \mathrm{~b}}\right), 124.0\left(\mathrm{C}_{12 \mathrm{a}}\right), 123.1\left(\mathrm{C}_{9}\right), 122.0$ $\left(\mathrm{C}_{8}\right), 121.3\left(\mathrm{C}_{10}\right), 113.1\left(\mathrm{C}_{7 \mathrm{a}}\right), 111.9\left(\mathrm{C}_{3 \mathrm{a}}\right), 110.5\left(\mathrm{C}_{11}\right), 29.3\left(\mathrm{C}_{6}\right), 27.8\left(\mathrm{C}_{5}\right)$, $26.5\left(\mathrm{C}_{7}\right), 25.2\left(\mathrm{C}_{4}\right)$; MS: $\mathrm{m} / z\left(\mathrm{M}^{+}, 238\right)$; Anal. calcd. for: $\mathrm{C}_{15} \mathrm{H}_{14} \mathrm{~N}_{2} \mathrm{O}: \mathrm{C}$, 75.61; H, 5.92; N, 11.76. Found: C, 75.66; H, 5.88; N, $11.80 \%$.

General procedure for the synthesis of 1-phenyl-4,5,6,7tetrahydropyrazolo $\left[4^{\prime}, 5^{\prime}: 8,7\right]-12 H$-cycloocta $[b]$ indoles (5): The reaction mixture consisting of the appropriate 7-(hydroxymethylene)$5,7,8,9,10,11$-hexahydrocycloocta[b]indol-6-one (2, $0.001 \mathrm{~mol})$, phenyl hydrazine $(0.54 \mathrm{~g})$ and glacial acetic acid $(5 \mathrm{~mL})$ was refluxed at $120^{\circ} \mathrm{C}$ for $10 \mathrm{~h}$. After the completion of the reaction, it was cooled and poured into crushed ice, the solid thus separated out was filtered, washed with water, dried and purified by column chromatography (eluent: petroleum ether:ethyl acetate, 97:3) and recrystallized from ethanol to give the respective 1-phenyl-4,5,6,7-tetrahydropyrazolo[3',4':8,7]-12Hcycloocta $[b]$ indole (5).

9-Methyl-1-phenyl-4,5,6,7-tetrahydropyrazolo[ $\left[3^{\prime}, 4^{\prime}: 8,7\right]-12 H$ cycloocta $[\boldsymbol{b}]$ indole $(5 a)$ : Yellow solid; yield: $66 \%$; m.p.203-205 ${ }^{\circ} \mathrm{C}$; IR $\left(\mathrm{KBr}, \mathrm{cm}^{-1}\right) v_{\max }: 3321(\mathrm{~N}-\mathrm{H}), 1623(\mathrm{C}=\mathrm{N}) ;{ }^{1} \mathrm{H}$ NMR $\left(500 \mathrm{MHz}, \mathrm{CDCl}_{3}\right)$ $(\mathrm{ppm}) \delta_{\mathrm{H}}: 7.53\left(\mathrm{~s}, 1 \mathrm{H}, \mathrm{C}_{3}-\mathrm{H}\right), 7.07\left(\mathrm{~b} \mathrm{~s}, 1 \mathrm{H}, \mathrm{N}_{12}-\mathrm{H}\right), 7.72-6.90(\mathrm{~m}, 8 \mathrm{H}$, $\mathrm{C}_{8}, \mathrm{C}_{10}, \mathrm{C}_{11}, \mathrm{C}_{2}{ }^{\prime}, \mathrm{C}_{3}{ }^{\prime}, \mathrm{C}_{4}{ }_{4}, \mathrm{C}_{5}{ }^{\prime}$ and $\left.\mathrm{C}_{6}^{\prime}-\mathrm{H}\right), 3.18-2.77\left(\mathrm{~m}, 4 \mathrm{H}, \mathrm{C}_{4}\right.$ and $\mathrm{C}_{7}-$ $\mathrm{H}), 2.40\left(\mathrm{~s}, 3 \mathrm{H}, \mathrm{C}_{9}-\mathrm{CH}_{3}\right), 1.80-1.59\left(\mathrm{~m}, 4 \mathrm{H}, \mathrm{C}_{5}\right.$ and $\left.\mathrm{C}_{6}-\mathrm{H}\right) ;{ }^{13} \mathrm{C}$ NMR $\left(125 \mathrm{MHz}, \mathrm{CDCl}_{3}\right)(\mathrm{ppm}) \delta_{\mathrm{C}}: 140.7\left(\mathrm{C}_{1}^{\prime}\right), 138.0\left(\mathrm{C}_{3}\right), 133.1\left(\mathrm{C}_{11 \mathrm{a}}\right), 130.8$ $\left(\mathrm{C}_{9}\right), 129.2\left(\mathrm{C}_{3}^{\prime}\right.$ and $\left.\mathrm{C}_{5}^{\prime}\right), 127.5\left(\mathrm{C}_{2}^{\prime}\right.$ and $\left.\mathrm{C}_{6}{ }^{\prime}\right), 126.5\left(\mathrm{C}_{7 \mathrm{~b}}\right), 126.1\left(\mathrm{C}_{12 \mathrm{~b}}\right)$, $124.8\left(\mathrm{C}_{4}^{\prime}\right), 123.2\left(\mathrm{C}_{12 \mathrm{a}}\right), 122.4\left(\mathrm{C}_{8}\right), 121.6\left(\mathrm{C}_{10}\right), 119.3\left(\mathrm{C}_{3 \mathrm{a}}\right), 113.8\left(\mathrm{C}_{7 \mathrm{a}}\right)$, $111.4\left(\mathrm{C}_{11}\right), 29.5\left(\mathrm{C}_{6}\right), 28.3\left(\mathrm{C}_{5}\right), 26.7\left(\mathrm{C}_{7}\right), 25.3\left(\mathrm{C}_{4}\right), 21.3\left(\mathrm{C}_{9}-\mathrm{CH}_{3}\right)$; MS: $m / z(\%) 327\left(\mathrm{M}^{+}, 327\right)$; Anal. calcd. for: $\mathrm{C}_{22} \mathrm{H}_{21} \mathrm{~N}_{3}: \mathrm{C}, 80.70 ; \mathrm{H}, 6.46 ; \mathrm{N}$, 12.83. Found: C, $80.75 ; \mathrm{H}, 6.41 ; \mathrm{N}, 12.79 \%$.

9-Chloro-1-phenyl-4,5,6,7-tetrahydropyrazolo [3',4':8,7]-12Hcycloocta $[\boldsymbol{b}]$ indole $(\mathbf{5 b})$ : Yellow solid; yield: $60 \%$; m.p.236-238 ${ }^{\circ} \mathrm{C}$; IR $\left(\mathrm{KBr}, \mathrm{cm}^{-1}\right) v_{\max }: 3327(\mathrm{~N}-\mathrm{H}), 1598(\mathrm{C}=\mathrm{N}) ;{ }^{1} \mathrm{H}$ NMR $\left(500 \mathrm{MHz}, \mathrm{CDCl}_{3}\right)$ $(\mathrm{ppm}) \delta_{\mathrm{H}}: 7.57\left(\mathrm{~s}, 1 \mathrm{H}, \mathrm{C}_{3}-\mathrm{H}\right), 7.16\left(\mathrm{~b} \mathrm{~s}, 1 \mathrm{H}, \mathrm{N}_{12}-\mathrm{H}\right), 7.45-6.95(\mathrm{~m}, 8 \mathrm{H}$, $\mathrm{C}_{8}, \mathrm{C}_{10}, \mathrm{C}_{11}, \mathrm{C}_{2}^{\prime}, \mathrm{C}_{3}{ }^{\prime}, \mathrm{C}_{4}^{\prime}, \mathrm{C}_{5}{ }^{\prime}$ and $\left.\mathrm{C}_{6}^{\prime}-\mathrm{H}\right), 3.32-1.62\left(\mathrm{~m}, 8 \mathrm{H}, \mathrm{C}_{4}, \mathrm{C}_{5}, \mathrm{C}_{6}\right.$ and $\left.\mathrm{C}_{7}-\mathrm{H}\right) ;{ }^{13} \mathrm{C}$ NMR $\left(125 \mathrm{MHz}, \mathrm{CDCl}_{3}\right)(\mathrm{ppm}) \delta_{\mathrm{C}}: 141.5\left(\mathrm{C}_{1}^{\prime}\right), 139.4\left(\mathrm{C}_{3}\right)$, $134.3\left(\mathrm{C}_{11 \mathrm{a}}\right), 129.2\left(\mathrm{C}_{3}^{\prime}\right.$ and $\left.\mathrm{C}_{5}{ }^{\prime}\right), 128.2\left(\mathrm{C}_{7 \mathrm{~b}}\right), 127.8\left(\mathrm{C}_{9}\right), 127.5\left(\mathrm{C}_{2}^{\prime}\right.$ and $\left.\mathrm{C}_{6}^{\prime}\right), 126.8\left(\mathrm{C}_{12 \mathrm{~b}}\right), 125.5\left(\mathrm{C}_{4}^{\prime}\right), 124.0\left(\mathrm{C}_{12 \mathrm{a}}\right), 122.8\left(\mathrm{C}_{8}\right), 121.2\left(\mathrm{C}_{10}\right), 118.4$ $\left(\mathrm{C}_{3 \mathrm{a}}\right), 112.6\left(\mathrm{C}_{7 \mathrm{a}}\right), 110.8\left(\mathrm{C}_{11}\right), 28.9\left(\mathrm{C}_{6}\right), 27.8\left(\mathrm{C}_{5}\right), 26.5\left(\mathrm{C}_{7}\right), 24.9\left(\mathrm{C}_{4}\right)$; MS: $m / z\left(\mathrm{M}^{+}, 347\right)$; Anal. calcd. for: $\mathrm{C}_{21} \mathrm{H}_{18} \mathrm{ClN}_{3}$ : C, $72.51 ; \mathrm{H}, 5.22 ; \mathrm{N}$, 12.08. Found: C, $72.55 ; \mathrm{H}, 5.17 ; \mathrm{N}, 12.13 \%$.

11-Methyl-1-phenyl-4,5,6,7-tetrahydropyrazolo $\left[3^{\prime}, 4^{\prime}: 8,7\right]-12 H$ cycloocta $[\boldsymbol{b}]$ indole $(5 \mathbf{c})$ : Yellow solid; yield: $63 \%$; m.p.220-222 ${ }^{\circ} \mathrm{C}$; IR $\left(\mathrm{KBr}, \mathrm{cm}^{-1}\right) v_{\max }: 3341(\mathrm{~N}-\mathrm{H}), 1605(\mathrm{C}=\mathrm{N}) ;{ }^{1} \mathrm{H}$ NMR $\left(500 \mathrm{MHz}, \mathrm{CDCl}_{3}\right)$ $(\mathrm{ppm}) \delta_{\mathrm{H}}: 7.63\left(\mathrm{~s}, 1 \mathrm{H}, \mathrm{C}_{3}-\mathrm{H}\right), 7.27\left(\mathrm{~b} \mathrm{~s}, 1 \mathrm{H}, \mathrm{N}_{12}-\mathrm{H}\right), 7.50-7.04(\mathrm{~m}, 8 \mathrm{H}$, $\mathrm{C}_{8}, \mathrm{C}_{9}, \mathrm{C}_{10}, \mathrm{C}_{2}^{\prime}, \mathrm{C}_{3}{ }^{\prime}, \mathrm{C}_{4}^{\prime}, \mathrm{C}_{5}^{\prime}$ and $\left.\mathrm{C}_{6}^{\prime}-\mathrm{H}\right), 2.93-2.67\left(\mathrm{~m}, 4 \mathrm{H}, \mathrm{C}_{4}\right.$ and $\mathrm{C}_{7}-$ $\mathrm{H}), 2.21\left(\mathrm{~s}, 3 \mathrm{H}, \mathrm{C}_{11}-\mathrm{CH}_{3}\right), 2.12-1.90\left(\mathrm{~m}, 4 \mathrm{H}, \mathrm{C}_{5}\right.$ and $\left.\mathrm{C}_{6}-\mathrm{H}\right) ;{ }^{13} \mathrm{C} \mathrm{NMR}$ $\left(125 \mathrm{MHz}, \mathrm{CDCl}_{3}\right)(\mathrm{ppm}) \delta_{\mathrm{C}}: 142.0\left(\mathrm{C}_{1}^{\prime}\right), 140.1\left(\mathrm{C}_{3}\right), 135.1\left(\mathrm{C}_{11 \mathrm{a}}\right), 129.8$ $\left(\mathrm{C}_{3}^{\prime}\right.$ and $\left.\mathrm{C}_{5}{ }^{\prime}\right), 128.0\left(\mathrm{C}_{2}^{\prime}\right.$ and $\left.\mathrm{C}_{6}^{\prime}\right), 127.3\left(\mathrm{C}_{7 \mathrm{~b}}\right), 126.0\left(\mathrm{C}_{12 \mathrm{~b}}\right), 125.3\left(\mathrm{C}_{4}^{\prime}\right)$, $124.7\left(\mathrm{C}_{122}\right), 123.8\left(\mathrm{C}_{9}\right), 122.5\left(\mathrm{C}_{10}\right), 121.9\left(\mathrm{C}_{11}\right), 119.4\left(\mathrm{C}_{8}\right), 117.6\left(\mathrm{C}_{3 \mathrm{a}}\right)$, $112.8\left(\mathrm{C}_{7 \mathrm{a}}\right), 29.1\left(\mathrm{C}_{6}\right), 28.6\left(\mathrm{C}_{5}\right), 26.8\left(\mathrm{C}_{7}\right), 25.2\left(\mathrm{C}_{4}\right), 18.8\left(\mathrm{C}_{11}-\mathrm{CH}_{3}\right)$; MS: $m / z\left(\mathrm{M}^{+}, 327\right)$; Anal. Calcd. for: $\mathrm{C}_{22} \mathrm{H}_{21} \mathrm{~N}_{3}: \mathrm{C}, 80.70 ; \mathrm{H}, 6.46 ; \mathrm{N}, 12.83$. Found: $\mathrm{C}, 80.75 ; \mathrm{H}, 6.41 ; \mathrm{N}, 12.79 \%$.

1-Phenyl-4,5,6,7-tetrahydropyrazolo [ $\left.3^{\prime}, 4^{\prime}: 8,7\right]-12 H$ cycloocta $[\boldsymbol{b}]$ indole (5d): Yellow solid; yield: $61 \%$; m.p. $244-246^{\circ} \mathrm{C}$; IR $\left(\mathrm{KBr}, \mathrm{cm}^{-1}\right) v_{\max }: 3334(\mathrm{~N}-\mathrm{H}), 1595(\mathrm{C}=\mathrm{N}) ;{ }^{1} \mathrm{H}$ NMR $\left(500 \mathrm{MHz}, \mathrm{CDCl}_{3}\right)$ (ppm) $\delta_{\mathrm{H}}: 7.60\left(\mathrm{~s}, 1 \mathrm{H}, \mathrm{C}_{3}-\mathrm{H}\right), 7.23\left(\mathrm{~b} \mathrm{~s}, 1 \mathrm{H}, \mathrm{N}_{12}-\mathrm{H}\right), 7.49-6.92(\mathrm{~m}, 9 \mathrm{H}$, $\mathrm{C}_{8}, \mathrm{C}_{9}, \mathrm{C}_{10}, \mathrm{C}_{11}, \mathrm{C}_{2}{ }^{\prime}, \mathrm{C}_{3}{ }^{\prime}, \mathrm{C}_{4}{ }^{\prime}, \mathrm{C}_{5}{ }^{\prime}$ and $\left.\mathrm{C}_{6}{ }^{\prime}-\mathrm{H}\right), 3.00-1.91\left(\mathrm{~m}, 8 \mathrm{H}, \mathrm{C}_{4}, \mathrm{C}_{5}, \mathrm{C}_{6}\right.$ 
Citation: Vairavelu L, Vellingiri M, Prasad KJR (2016) Synthesis, Biological Evaluation and Structure Activity Relationship of Substituted pyrazolo-, isoxazolo-, pyrimido- and mercaptopyrimidocycloocta[b]indoles. Med chem (Los Angeles) 6: 356-364. doi:10.4172/2161-0444.1000370

and $\left.\mathrm{C}_{7}-\mathrm{H}\right) ;{ }^{13} \mathrm{C}$ NMR $\left(125 \mathrm{MHz}, \mathrm{CDCl}_{3}\right)(\mathrm{ppm}) \delta_{\mathrm{C}}: 140.1\left(\mathrm{C}_{1}^{\prime}\right), 138.5$ $\left(\mathrm{C}_{3}\right), 135.0\left(\mathrm{C}_{112}\right), 129.6\left(\mathrm{C}_{3}^{\prime}\right.$ and $\left.\mathrm{C}_{5}^{\prime}\right), 127.8\left(\mathrm{C}_{7 \mathrm{~b}}\right), 126.9\left(\mathrm{C}_{2}^{\prime}\right.$ and $\left.\mathrm{C}_{6}^{\prime}\right)$, $125.7\left(\mathrm{C}_{12 \mathrm{~b}}\right), 124.5\left(\mathrm{C}_{4}^{\prime}\right), 124.0\left(\mathrm{C}_{12 \mathrm{a}}\right), 123.8\left(\mathrm{C}_{9}\right), 122.1\left(\mathrm{C}_{8}\right), 121.5\left(\mathrm{C}_{10}\right)$, $116.4\left(\mathrm{C}_{3 \mathrm{a}}\right), 113.9\left(\mathrm{C}_{7 \mathrm{a}}\right), 112.5\left(\mathrm{C}_{11}\right), 29.0\left(\mathrm{C}_{6}\right), 28.3\left(\mathrm{C}_{5}\right), 27.8\left(\mathrm{C}_{7}\right), 25.4$ $\left(\mathrm{C}_{4}\right)$; MS: $m / z\left(\mathrm{M}^{+}, 313\right)$; Anal. calcd. for: $\mathrm{C}_{21} \mathrm{H}_{19} \mathrm{~N}_{3}: \mathrm{C}, 80.48 ; \mathrm{H}, 6.11 ; \mathrm{N}$, 13.41. Found: $\mathrm{C}, 80.53 ; \mathrm{H}, 6.16 ; \mathrm{N}, 13.45 \%$.

General procedure for the synthesis of 2-hydroxy-5,6,7,8tetrahydropyrimido $\left[5^{\prime}, 6^{\prime}: 8,7\right]-13 H$-cycloocta $[b]$ indoles (6): A mixture of an appropriate 7-(hydroxymethylene)-5,7,8,9,10,11hexahydrocycloocta[ $b]$ indol-6-one $(2,0.001 \mathrm{~mol})$, urea $(0.12 \mathrm{~g})$ and glacial acetic acid $(6 \mathrm{~mL})$ was refluxed at $120^{\circ} \mathrm{C}$ for $5 \mathrm{~h}$. After the completion of the reaction, it was cooled and poured into crushed ice with stirring. The solid thus separated out was filtered, dried and purified by column chromatography (eluent: petroleum ether:ethyl acetate, 75:25) and recrystallized from ethanol to give the respective 2-hydroxy-5,6,7,8-tetrahydropyrimido $\left[5^{\prime}, 6^{\prime}: 8,7\right]$-13H-cycloocta[ $\left.b\right]$ indole (6).

2-Hydroxy-10-methyl-5,6,7,8-tetrahydropyrimido $\left[5^{\prime}, 6^{\prime}: 8,7\right]$ $13 \mathrm{H}$-cycloocta $[\boldsymbol{b}]$ indole $(6 a)$ : Yellow solid; yield: $71 \%$; m.p.222-224 ${ }^{\circ} \mathrm{C}$; IR $\left(\mathrm{KBr}, \mathrm{cm}^{-1}\right) ; v_{\max }: 3418(\mathrm{O}-\mathrm{H}), 3251(\mathrm{~N}-\mathrm{H}), 1621(\mathrm{C}=\mathrm{N}) ;{ }^{1} \mathrm{H}$ NMR $\left(500 \mathrm{MHz} \mathrm{CDCl}_{3}\right)(\mathrm{ppm}) \delta_{\mathrm{H}}: 11.68\left(\mathrm{~s}, 1 \mathrm{H}, \mathrm{C}_{2}-\mathrm{OH}\right), 9.38(\mathrm{~b} \mathrm{~s}, 1 \mathrm{H}$, $\left.\mathrm{N}_{13}-\mathrm{H}\right)$, 7.54-7.11 (m, 4H, C $, \mathrm{C}_{9}, \mathrm{C}_{11}$ and $\left.\mathrm{C}_{12}-\mathrm{H}\right)$, 3.03-2.82 (m, $4 \mathrm{H}, \mathrm{C}_{5}$ and $\left.\mathrm{C}_{8}-\mathrm{H}\right), 2.42\left(\mathrm{~s}, 3 \mathrm{H}, \mathrm{C}_{10}-\mathrm{CH}_{3}\right), 1.78-1.57\left(\mathrm{~m}, 4 \mathrm{H}, \mathrm{C}_{6}\right.$ and $\left.\mathrm{C}_{7}-\mathrm{H}\right) ;{ }^{13} \mathrm{C}$ $\operatorname{NMR}\left(125 \mathrm{MHz}, \mathrm{CDCl}_{3}\right)(\mathrm{ppm}) \delta_{\mathrm{C}}: 162.4\left(\mathrm{C}_{2}\right), 150.2\left(\mathrm{C}_{4}\right), 146.9\left(\mathrm{C}_{13 \mathrm{~b}}\right)$, 134.6 $\left(\mathrm{C}_{12 \mathrm{a}}\right), 131.9\left(\mathrm{C}_{10}\right), 129.0\left(\mathrm{C}_{8 \mathrm{~b}}\right), 124.0\left(\mathrm{C}_{13 \mathrm{a}}\right), 121.0\left(\mathrm{C}_{9}\right), 120.2\left(\mathrm{C}_{11}\right)$, $118.6\left(\mathrm{C}_{4 \mathrm{a}}\right), 113.2\left(\mathrm{C}_{8 \mathrm{a}}\right), 110.4\left(\mathrm{C}_{12}\right), 27.9\left(\mathrm{C}_{7}\right), 25.1\left(\mathrm{C}_{6}\right), 23.6\left(\mathrm{C}_{8}\right), 22.6$ $\left(\mathrm{C}_{5}\right), 21.6\left(\mathrm{C}_{10}-\mathrm{CH}_{3}\right) ; \mathrm{MS}: \mathrm{m} / z\left(\mathrm{M}^{+}, 279\right)$; Anal. calcd. for: $\mathrm{C}_{17} \mathrm{H}_{17} \mathrm{~N}_{3} \mathrm{O}: \mathrm{C}$, 73.10; H, 6.13; N, 15.04. Found: C, 73.15; H, 6.18; N, 15.10\%.

2-Hydroxy-10-chloro-5,6,7,8-tetrahydropyrimido[5',6':8,7]-13Hcycloocta $[\boldsymbol{b}]$ indole $(\mathbf{6 b})$ : Yellow solid; yield: $70 \%$; m.p.198-200 ${ }^{\circ} \mathrm{C}$; IR $\left(\mathrm{KBr}, \mathrm{cm}^{-1}\right) v_{\text {max }}: 3424(\mathrm{O}-\mathrm{H}), 3275(\mathrm{~N}-\mathrm{H}), 1608(\mathrm{C}=\mathrm{N})$; ${ }^{1} \mathrm{H}$ NMR $(500$ $\mathrm{MHz}, \mathrm{CDCl}_{3}$ ) (ppm) $\delta_{\mathrm{H}}: 11.38\left(\mathrm{~s}, 1 \mathrm{H}, \mathrm{C}_{2}-\mathrm{OH}\right), 9.21\left(\mathrm{~b} \mathrm{~s}, 1 \mathrm{H}, \mathrm{N}_{13}-\mathrm{H}\right)$, 7.39-7.03 (m, $4 \mathrm{H}, \mathrm{C}_{4}, \mathrm{C}_{9}, \mathrm{C}_{11}$ and $\left.\mathrm{C}_{12}-\mathrm{H}\right), 3.00-1.63\left(\mathrm{~m}, 8 \mathrm{H}, \mathrm{C}_{5}, \mathrm{C}_{6}, \mathrm{C}_{7}\right.$ and $\left.\mathrm{C}_{8}-\mathrm{H}\right) ;{ }^{13} \mathrm{C}$ NMR $\left(125 \mathrm{MHz}, \mathrm{CDCl}_{3}\right)(\mathrm{ppm}) \delta_{\mathrm{C}}: 165.1\left(\mathrm{C}_{2}\right), 153.2$ $\left(\mathrm{C}_{4}\right), 148.3\left(\mathrm{C}_{13 \mathrm{~b}}\right), 133.4\left(\mathrm{C}_{12 \mathrm{a}}\right), 130.4\left(\mathrm{C}_{8 \mathrm{~b}}\right), 129.2\left(\mathrm{C}_{10}\right), 123.4\left(\mathrm{C}_{13 \mathrm{a}}\right), 122.0$ $\left(\mathrm{C}_{9}\right), 121 .\left(\mathrm{C}_{11}\right), 119.1\left(\mathrm{C}_{4 \mathrm{a}}\right), 112.5\left(\mathrm{C}_{8 \mathrm{a}}\right), 111.6\left(\mathrm{C}_{12}\right), 28.5\left(\mathrm{C}_{6}\right), 27.6\left(\mathrm{C}_{7}\right)$, $25.2\left(\mathrm{C}_{8}\right), 24.3\left(\mathrm{C}_{5}\right)$; $\mathrm{MS}: \mathrm{m} / z\left(\mathrm{M}^{+}, 299\right)$; Anal. calcd. for: $\mathrm{C}_{16} \mathrm{H}_{14} \mathrm{ClN}_{3} \mathrm{O}: \mathrm{C}$, 64.11; H, 4.71; N, 14.02. Found: C, 64.16; H, 4.67; N, 14.08\%.

2-Hydroxy-12-methyl-5,6,7,8-tetrahydropyrimido [5',6':8,7]$13 \mathrm{H}$-cycloocta $[\boldsymbol{b}]$ indole $(\mathbf{6 c})$ : Yellow solid; yield: $74 \%$; m.p. $214-216^{\circ} \mathrm{C}$; IR $\left(\mathrm{KBr}, \mathrm{cm}^{-1}\right) v_{\max }: 3476(\mathrm{O}-\mathrm{H}), 3308(\mathrm{~N}-\mathrm{H}), 1602(\mathrm{C}=\mathrm{N}) ;{ }^{1} \mathrm{H}$ NMR $\left(500 \mathrm{MHz} \mathrm{CDCl}_{3}\right)(\mathrm{ppm}) \delta_{\mathrm{H}}: 11.10\left(\mathrm{~s}, 1 \mathrm{H}, \mathrm{C}_{2}-\mathrm{OH}\right), 8.99$ (b s, $1 \mathrm{H}$, $\left.\mathrm{N}_{13}-\mathrm{H}\right), 7.50-7.08\left(\mathrm{~m}, 4 \mathrm{H}, \mathrm{C}_{4}, \mathrm{C}_{9}, \mathrm{C}_{10}\right.$ and $\left.\mathrm{C}_{11}-\mathrm{H}\right), 3.10-2.75\left(\mathrm{~m}, 4 \mathrm{H}, \mathrm{C}_{5}\right.$ and $\left.\mathrm{C}_{8}-\mathrm{H}\right), 2.50\left(\mathrm{~s}, 3 \mathrm{H}, \mathrm{C}_{12}-\mathrm{CH}_{3}\right), 1.98-1.66\left(\mathrm{~m}, 4 \mathrm{H}, \mathrm{C}_{6}\right.$ and $\left.\mathrm{C}_{7}-\mathrm{H}\right) ;{ }^{13} \mathrm{C}$ $\operatorname{NMR}\left(125 \mathrm{MHz}, \mathrm{CDCl}_{3}\right)(\mathrm{ppm}) \delta_{\mathrm{C}}: 160.7\left(\mathrm{C}_{2}\right), 151.5\left(\mathrm{C}_{4}\right), 145.5\left(\mathrm{C}_{13 \mathrm{~b}}\right)$, $135.7\left(\mathrm{C}_{12 \mathrm{a}}\right), 131.0\left(\mathrm{C}_{8 \mathrm{~b}}\right), 124.6\left(\mathrm{C}_{13 \mathrm{a}}\right), 123.6\left(\mathrm{C}_{10}\right), 121.0\left(\mathrm{C}_{11}\right), 120.8\left(\mathrm{C}_{12}\right)$, $119.8\left(\mathrm{C}_{9}\right), 118.6\left(\mathrm{C}_{4 \mathrm{a}}\right), 113.2\left(\mathrm{C}_{8 \mathrm{a}}\right), 27.9\left(\mathrm{C}_{6}\right), 25.1\left(\mathrm{C}_{7}\right), 23.6\left(\mathrm{C}_{8}\right), 22.6$ $\left(\mathrm{C}_{5}\right), 19.2\left(\mathrm{C}_{12}-\mathrm{CH}_{3}\right) ; \mathrm{MS}: \mathrm{m} / z\left(\mathrm{M}^{+}, 279\right)$; Anal. calcd. for: $\mathrm{C}_{17} \mathrm{H}_{17} \mathrm{~N}_{3} \mathrm{O}: \mathrm{C}$, $73.10 ; \mathrm{H}, 6.13 ; \mathrm{N}, 15.04$. Found: C, 73.15; H, 6.18; N, 15.10\%.

General procedure for the synthesis of 2-mercapto-5,6,7,8tetrahydropyrimido $\left[5^{\prime}, 6^{\prime}: 8,7\right]-13 H$-cycloocta $[b]$ indoles (7): A mixture of an appropriate 7-(hydroxymethylene)-5,7,8,9,10,11hexahydrocycloocta[b]indol-6-one $(2,0.001 \mathrm{~mol})$, thiourea $(0.152$ g) and glacial acetic acid $(6 \mathrm{~mL})$ was refluxed at $120^{\circ} \mathrm{C}$ for $5 \mathrm{~h}$. After the completion of the reaction, it was cooled and poured into crushed ice with stirring. The solid thus separated out was filtered, dried and purified by column chromatography (eluent: petroleum ether:ethyl acetate, 75:25) and recrystallized from ethanol to give the respective 2-mercapto-5,6,7,8-tetrahydropyrimido $\left[5^{\prime}, 6^{\prime}: 8,7\right]-13 H$-cycloocta[ $\left.b\right]$ indole (7).
2-Mercapto-10-methyl-5,6,7,8-tetrahydropyrimido [5',6':8,7]$13 \mathrm{H}$-cycloocta $[\boldsymbol{b}]$ indole (7a): Yellow solid; yield: $74 \%$; m.p. $248-250^{\circ} \mathrm{C}$; IR $\left(\mathrm{KBr}, \mathrm{cm}^{-1}\right) v_{\max }: 3423(\mathrm{~N}-\mathrm{H}), 1155(\mathrm{C}=\mathrm{S}) ;{ }^{1} \mathrm{H}$ NMR $(500 \mathrm{MHz}$, $\left.\mathrm{CDCl}_{3}\right)(\mathrm{ppm}) \delta_{\mathrm{H}}: 8.89\left(\mathrm{~b} \mathrm{~s}, 1 \mathrm{H}, \mathrm{N}_{13}-\mathrm{H}\right), 7.76-7.04\left(\mathrm{~m}, 4 \mathrm{H}, \mathrm{C}_{4}, \mathrm{C}_{9}, \mathrm{C}_{11}\right.$ and $\left.\mathrm{C}_{12}-\mathrm{H}\right), 3.19-2.92\left(\mathrm{~m}, 5 \mathrm{H}, \mathrm{C}_{2}-\mathrm{SH}, \mathrm{C}_{5}\right.$ and $\left.\mathrm{C}_{8}-\mathrm{H}\right), 2.36\left(\mathrm{~s}, 3 \mathrm{H}, \mathrm{C}_{10^{-}}\right.$ $\left.\mathrm{CH}_{3}\right), 2.05-1.89\left(\mathrm{~m}, 4 \mathrm{H}, \mathrm{C}_{6}\right.$ and $\left.\mathrm{C}_{7}-\mathrm{H}\right) ;{ }^{13} \mathrm{C} \mathrm{NMR}\left(125 \mathrm{MHz}, \mathrm{CDCl}_{3}\right)$ $(\mathrm{ppm}) \delta_{\mathrm{C}}: 172.2\left(\mathrm{C}_{2}\right), 153.9\left(\mathrm{C}_{4}\right), 152.0\left(\mathrm{C}_{13 \mathrm{~b}}\right), 133.4\left(\mathrm{C}_{12 \mathrm{a}}\right), 130.8\left(\mathrm{C}_{10}\right)$, $127.8\left(\mathrm{C}_{8 \mathrm{~b}}\right), 126.1\left(\mathrm{C}_{13 \mathrm{a}}\right), 122.1\left(\mathrm{C}_{9}\right), 121.3\left(\mathrm{C}_{11}\right), 120.4\left(\mathrm{C}_{4 \mathrm{a}}\right), 115.8\left(\mathrm{C}_{8 \mathrm{a}}\right)$, 113.7 $\left(\mathrm{C}_{12}\right), 29.4\left(\mathrm{C}_{7}\right), 27.9\left(\mathrm{C}_{6}\right), 24.8\left(\mathrm{C}_{8}\right), 23.7\left(\mathrm{C}_{5}\right), 21.4\left(\mathrm{C}_{10}-\mathrm{CH}_{3}\right)$; MS: $m / z\left(\mathrm{M}^{+}, 295\right)$; Anal. calcd. for: $\mathrm{C}_{17} \mathrm{H}_{17} \mathrm{~N}_{3} \mathrm{~S}: \mathrm{C}, 69.12 ; \mathrm{H}, 5.80 ; \mathrm{N}, 14.22 ; \mathrm{S}$, 10.85. Found: C, $69.18 ; \mathrm{H}, 5.75 ; \mathrm{N}, 14.17 ; \mathrm{S}, 10.90 \%$.

2-Mercapto-10-chloro-5,6,7,8-tetrahydropyrimido [5',6':8,7]$13 \mathrm{H}$-cycloocta $[\boldsymbol{b}]$ indole $(7 \mathrm{~b})$ : Yellow solid; yield: $69 \%$; m.p. $265-267^{\circ} \mathrm{C}$; IR $\left(\mathrm{KBr}, \mathrm{cm}^{-1}\right) v_{\max }: 3395(\mathrm{~N}-\mathrm{H}), 1158(\mathrm{C}=\mathrm{S}) ;{ }^{1} \mathrm{H}$ NMR $(500 \mathrm{MHz}$, $\left.\mathrm{CDCl}_{3}\right)(\mathrm{ppm}) \delta_{\mathrm{H}}: 8.85\left(\mathrm{~b} \mathrm{~s}, 1 \mathrm{H}, \mathrm{N}_{13}-\mathrm{H}\right), 7.68-7.10\left(\mathrm{~m}, 4 \mathrm{H}, \mathrm{C}_{4}, \mathrm{C}_{9}, \mathrm{C}_{11}\right.$ and $\left.\mathrm{C}_{12}-\mathrm{H}\right), 3.44-2.10\left(\mathrm{~m}, 9 \mathrm{H}, \mathrm{C}_{2}-\mathrm{SH}, \mathrm{C}_{5}, \mathrm{C}_{6}, \mathrm{C}_{7}\right.$ and $\left.\mathrm{C}_{8}-\mathrm{H}\right) ;{ }^{13} \mathrm{C}$ NMR $\left(125 \mathrm{MHz}, \mathrm{CDCl}_{3}\right)(\mathrm{ppm}) \delta_{\mathrm{C}}: 173.6\left(\mathrm{C}_{2}\right), 155.3\left(\mathrm{C}_{4}\right), 151.4\left(\mathrm{C}_{13 \mathrm{~b}}\right), 134.5$ $\left(\mathrm{C}_{12 \mathrm{a}}\right), 132.1\left(\mathrm{C}_{10}\right), 128.1\left(\mathrm{C}_{8 \mathrm{~b}}\right), 125.5\left(\mathrm{C}_{13 \mathrm{a}}\right), 121.1\left(\mathrm{C}_{9}\right), 120.8\left(\mathrm{C}_{11}\right), 120.6$ $\left(\mathrm{C}_{4 \mathrm{a}}\right), 114.8\left(\mathrm{C}_{8 \mathrm{a}}\right), 112.6\left(\mathrm{C}_{12}\right), 28.6\left(\mathrm{C}_{7}\right), 27.2\left(\mathrm{C}_{6}\right), 26.7\left(\mathrm{C}_{8}\right), 24.6\left(\mathrm{C}_{5}\right)$; MS: $m / z\left(\mathrm{M}^{+}, 315\right)$; Anal. calcd. for: $\mathrm{C}_{16} \mathrm{H}_{14} \mathrm{ClN}_{3} \mathrm{~S}: \mathrm{C}, 60.85 ; \mathrm{H}, 4.47 ; \mathrm{N}$, $13.31 ; \mathrm{S}, 10.15$. Found: C, $60.81 ; \mathrm{H}, 4.52 ; \mathrm{N}, 13.27$;, $10.20 \%$.

2-Mercapto-12-methyl-5,6,7,8-tetrahydropyrimido[5',6':8,7]$13 \mathrm{H}$-cycloocta $\left[\boldsymbol{b}\right.$ ] indole $(7 \mathrm{c})$ : Yellow solid; yield: $72 \%$; m.p. $244-246^{\circ} \mathrm{C}$; IR $\left(\mathrm{KBr}, \mathrm{cm}^{-1}\right) v_{\max }: 3378(\mathrm{~N}-\mathrm{H}), 1152(\mathrm{C}=\mathrm{N}) ;{ }^{1} \mathrm{H}$ NMR $(500 \mathrm{MHz}$, $\left.\mathrm{CDCl}_{3}\right)(\mathrm{ppm}) \delta_{\mathrm{H}}: 9.08\left(\mathrm{~b} \mathrm{~s}, 1 \mathrm{H}, \mathrm{N}_{13}-\mathrm{H}\right), 7.62-7.18\left(\mathrm{~m}, 4 \mathrm{H}, \mathrm{C}_{4}, \mathrm{C}_{9}, \mathrm{C}_{10}\right.$ and $\left.\mathrm{C}_{12}-\mathrm{H}\right), 3.39-2.71\left(\mathrm{~m}, 5 \mathrm{H}, \mathrm{C}_{2}-\mathrm{SH}, \mathrm{C}_{5}\right.$ and $\left.\mathrm{C}_{8}-\mathrm{H}\right), 2.48\left(\mathrm{~s}, 3 \mathrm{H}, \mathrm{C}_{12}-\right.$ $\left.\mathrm{CH}_{3}\right), 2.09-1.96\left(\mathrm{~m}, 4 \mathrm{H}, \mathrm{C}_{6}\right.$ and $\left.\mathrm{C}_{7}-\mathrm{H}\right) ;{ }^{13} \mathrm{C}$ NMR $\left(125 \mathrm{MHz}, \mathrm{CDCl}_{3}\right)$ $(\mathrm{ppm}) \delta_{\mathrm{C}}: 170.6\left(\mathrm{C}_{2}\right), 152.4\left(\mathrm{C}_{4}\right), 151.5\left(\mathrm{C}_{13 \mathrm{~b}}\right), 136.2\left(\mathrm{C}_{12 \mathrm{a}}\right), 128.5\left(\mathrm{C}_{8 \mathrm{~b}}\right)$, $127.0\left(\mathrm{C}_{13 \mathrm{a}}\right), 124.1\left(\mathrm{C}_{10}\right), 122.1\left(\mathrm{C}_{11}\right), 121.3\left(\mathrm{C}_{12}\right), 120.4\left(\mathrm{C}_{4 \mathrm{a}}\right), 119.9\left(\mathrm{C}_{9}\right)$, $114.2\left(\mathrm{C}_{8 \mathrm{a}}\right), 28.1\left(\mathrm{C}_{7}\right), 27.2\left(\mathrm{C}_{6}\right), 26.5\left(\mathrm{C}_{8}\right), 25.3\left(\mathrm{C}_{5}\right), 18.8\left(\mathrm{C}_{12}-\mathrm{CH}_{3}\right)$; MS $\mathrm{m} / z\left(\mathrm{M}^{+}, 295\right)$; Anal. calcd. for: $\mathrm{C}_{17} \mathrm{H}_{17} \mathrm{~N}_{3} \mathrm{~S}: \mathrm{C}, 69.12 ; \mathrm{H}, 5.80 ; \mathrm{N}, 14.22$; S, 10.85. Found: C, 69.18; H, 5.75; N, 14.17; S, 10.90\%.

2-Mercapto-5,6,7,8-tetrahydropyrimido $\left[5^{\prime}, 6^{\prime}: 8,7\right]-13 H$ cycloocta $[\boldsymbol{b}]$ indole (7d): Yellow solid; yield: $70 \%$; m.p.211-213 ${ }^{\circ} \mathrm{C}$; IR $\left(\mathrm{KBr}, \mathrm{cm}^{-1}\right) v_{\max }: 3360(\mathrm{~N}-\mathrm{H}), 1157(\mathrm{C}=\mathrm{N}) ;{ }^{1} \mathrm{H} \mathrm{NMR}\left(500 \mathrm{MHz}, \mathrm{CDCl}_{3}\right)$ (ppm) $\delta_{\mathrm{H}}: 9.20\left(\mathrm{~b} \mathrm{~s}, 1 \mathrm{H}, \mathrm{N}_{13}-\mathrm{H}\right), 7.70-7.10\left(\mathrm{~m}, 5 \mathrm{H}, \mathrm{C}_{4}, \mathrm{C}_{9}, \mathrm{C}_{10}, \mathrm{C}_{11}\right.$ and $\left.\mathrm{C}_{12}-\mathrm{H}\right), 3.49-1.56\left(\mathrm{~m}, 9 \mathrm{H}, \mathrm{C}_{2}-\mathrm{SH}, \mathrm{C}_{5}, \mathrm{C}_{6}, \mathrm{C}_{7}\right.$ and $\left.\mathrm{C}_{8}-\mathrm{H}\right) ;{ }^{13} \mathrm{C}$ NMR $(125$ $\left.\mathrm{MHz}, \mathrm{CDCl}_{3}\right)(\mathrm{ppm}) \delta_{\mathrm{C}}: 171.3\left(\mathrm{C}_{2}\right), 153.5\left(\mathrm{C}_{4}\right), 152.5\left(\mathrm{C}_{13 \mathrm{~b}}\right), 133.8\left(\mathrm{C}_{12 \mathrm{a}}\right)$, $129.3\left(\mathrm{C}_{8 \mathrm{~b}}\right), 124.6\left(\mathrm{C}_{13 \mathrm{a}}\right), 122.9\left(\mathrm{C}_{10}\right), 121.8\left(\mathrm{C}_{9}\right), 120.5\left(\mathrm{C}_{11}\right), 119.5\left(\mathrm{C}_{4 \mathrm{a}}\right)$, $112.9\left(\mathrm{C}_{8 \mathrm{a}}\right), 111.7\left(\mathrm{C}_{12}\right), 28.9\left(\mathrm{C}_{7}\right), 28.0\left(\mathrm{C}_{6}\right), 27.2\left(\mathrm{C}_{8}\right), 25.7\left(\mathrm{C}_{5}\right)$; MS: $\mathrm{m} / z\left(\mathrm{M}^{+}, 281\right)$; Anal. calcd. for: $\mathrm{C}_{16} \mathrm{H}_{15} \mathrm{~N}_{3} \mathrm{~S}: \mathrm{C}, 68.30 ; \mathrm{H}, 5.37 ; \mathrm{N}, 14.93$; S, 11.40. Found: C, $68.35 ; \mathrm{H}, 5.31 ; \mathrm{N}, 15.00 ; \mathrm{S}, 11.35 \%$.

\section{Biology}

Anti-bacterial activity: The anti- microbial activity was done by well diffusion method (Cappuccino and Sherman) against the test organism such as Staphylococcus aureus, Staphylococcus epidermis, Enterococcus sp, Escherichia coli, Pseudomonas aeruginosa, Klebsiella $s p$, Salmonella sp, Proteus sp, Shigella sp, Bacillus sp, and Candida albicans. By using a sterile cork borer, wells were punctured in Mueller Hinton agar plates previously seeded with one of the test organism. One hundred microliter of supernatant of each isolate was added in each well. The diameters of inhibition were determined after $24 \mathrm{~h}$ of incubation at $37^{\circ} \mathrm{C}$.

Anti tumor activity: Cytotoxicity studies of the compounds along with Doxorubicin were carried out on MCF-7 breast cancer and in A549 non-small cell lung cancer (NSCLC) celllines and which were obtained from National Centre for Cell Science, Pune, India. Cell viability was carried out using the MTT assay method. The HeLa and AGS cells were grown in Eagles minimum essential medium containing 10\% fetal 
bovine serum (FBS). For the screening experiment, the cells were seeded into 96 -well plates in $100 \mu \mathrm{L}$ of the respective medium containing $10 \%$ FBS, at a plating density of 10,000 cells/well, and incubated at $37^{\circ} \mathrm{C}$, under conditions of $5 \% \mathrm{CO}_{2}, 95 \%$ air, and $100 \%$ relative humidity for 24 $\mathrm{h}$ prior to the addition of compounds. The compounds were dissolved in DMSO and diluted in the respective medium containing $1 \%$ FBS. After $24 \mathrm{~h}$, the medium was replaced with the respective medium with $1 \%$ FBS containing the compounds at various concentrations and incubated at $37{ }^{\circ} \mathrm{C}$ under conditions of $5 \% \mathrm{CO}_{2}, 95 \%$ air, and $100 \%$ relative humidity for $48 \mathrm{~h}$. After $48 \mathrm{~h}, 10 \mu \mathrm{L}$ of MTT $(5 \mu \mathrm{g} / \mathrm{ml})$ in phosphate buffered saline (PBS) was added to each well and incubated at $37^{\circ} \mathrm{C}$ for $4 \mathrm{~h}$. The medium with MTT was then flicked off, and the formed formazan crystals were dissolved in $100 \mu \mathrm{L}$ of DMSO. The absorbance was then measured at $570 \mathrm{~nm}$ using a microplate reader. The percentage of cell inhibition was determined using the following formula, and a graph was plotted with the percentage of cell inhibition versus concentration. From this, the $\mathrm{IC}_{50}$ value was calculated: $\%$ inhibition $=[$ mean OD of untreated cells (control)/mean OD of treated cells (control) $] \times 100$. The results were expressed as the concentration at which there was $50 \%$ inhibition $\left(\mathrm{IC}_{50}\right)$.

\section{Results and Discussion}

\section{Chemistry}

Synthesis of isoxazolo-, pyrido- and pyrazolo- cycloocta[b] indoles: As part of our ongoing studies on the development of facile methods for the synthesis of organic compounds from readily available starting materials, specifically 7-(hydroxymethylene)-5,7,8,9,10,11hexahydrocycloocta[ $b]$ indol-6-ones (2), a putative synthon, which can be obtained by Claisen condensation of 5,7,8,9,10,11-hexahydrocyclo octa[ $b]$ indol-6-ones (1) with ethylformate in the presence of sodium methoxide as shown in Scheme 1. We would like to describe here the reaction of these readily available compounds (2) with hydrazine hydrate, hydroxylamine hydrochloride, phenylhydrazine, urea and thiourea leading to highly-substituted pyrazolo-, isoxazolo-, pyrimidoand mercaptopyrimidocycloocta $[b]$ indoles in one-pot addition reactions to form a library of new pyrazolo-, isoxazolo-, pyrimido- and mercaptopyrimidocycloocta[b] indoles (Scheme 2). IR, ${ }^{1} \mathrm{H}$ NMR, ${ }^{13} \mathrm{C}$ NMR data and elemental analyses were used to ascertain the structures of all compounds.

As a model reaction we initially investigate the reaction of 5,7,8,9,10,11-hexahydrocycloocta[ $b]$ indol-6-ones (1) with ethyl formate (Scheme 1). A major reason for our interest in these compounds was the possibility of their transformation into a number of annulated cycloocta[b]indoles possessing different heterocyclic systems using simple reactions with various agents. The structures of the products were substantiated on the basis of IR, ${ }^{1} \mathrm{H}$ NMR, ${ }^{13} \mathrm{C}$ NMR data and elemental analysis. The IR spectrum of $\mathbf{2 a}$ showed sharp and strong bands at 3313 and $1625 \mathrm{~cm}^{-1}$ assigned to hydroxyl (overlapped with $\mathrm{NH}$ ) and carbonyl group respectively. Further the disappearance of $\mathrm{C}_{7}$-methylene protons signals and the appearance of $\mathrm{OH}$ and olefinic- $\mathrm{CH}$ signals as two doublets at $\delta 15.62(J=8.05 \mathrm{~Hz})$ and $\delta 7.90$ $(J=8.05 \mathrm{~Hz})$ and also the appearance of carbazole $\mathrm{NH}$ proton at $\delta 8.89$ in its ${ }^{1} \mathrm{H}$-NMR spectrum suggested the structure of $\mathbf{2 a}$ to be a hydroxyl methylene compound. The rest of the aromatic protons appeared in the corresponding region.

In the next step we expanded the range of nucleophiles and investigated the construction of pyrazolo-, isoxazolo- and pyrimidocycloocta $[b]$ indoles from the precursor, 7-hydroxymethylene$5,7,8,9,10,11$-hexahydrocycloocta $[b]$ indol-6-ones (2) upon reaction with hydrazine hydrate, hydroxylamine hydrochloride, phenylhydrazine, urea and thiourea as shown in Scheme 2.

We first focused our attention towards the synthesis of pyrazolocycloocta[ $b]$ indoles 3 from 7 -hydroxymethylene-5,7,8,9,10,11hexahydrocycloocta $[b]$ indol-6-ones (2) upon reaction with hydrazine hydrate. The proton NMR spectrum of $\mathbf{3 a}$ revealed the appearance of two broad singlets at $\delta 9.01$ and $\delta 7.57$ accounted for indole-NH and pyrazolo- $\mathrm{NH}$ protons respectively. The other aromatic protons appeared as multiplet in the region $\delta$ 7.48-7.20. The remaining protons appear in the corresponding region. Mass spectrum and elemental analysis data support the molecular formula as $\mathrm{C}_{16} \mathrm{H}_{17} \mathrm{~N}_{3}$. The identities of the other compounds $\mathbf{3} \mathbf{b}$ to $\mathbf{3 d}$ were established in the same way with all spectroscopic data readily assignable.

In an anticipation to derive isoxazolocycloocta $[b]$ indoles (4), the corresponding 7-(hydroxymethylene)-5,7,8,9,10,11hexahydrocycloocta[b]indol-6-one (2) was treated with hydroxylamine hydrochloride in acetic acid. The IR spectrum of $\mathbf{4 a}$ registered absorption band at $1611 \mathrm{~cm}^{-1}$ assigned to $\mathrm{C}=\mathrm{N}$ functional group. The proton NMR spectrum of $\mathbf{4 a}$ showed one broad singlet at $\delta 8.93$ accounted for indole- $\mathrm{NH}$. The rest of the aromatic protons appeared as a multiplet between the region $\delta 8.19-7.09$. Analytical data are in accordance with the proposed structure for compound 4 .

In order to extend the above synthesis, we carried out the reaction of 7-(hydroxymethylene)-5,7,8,9,10,11-hexahydrocycloocta[b]indol-6one (2) with phenyl hydrazine in glacial acetic acid for $6 \mathrm{~h}$ to afford a single product (5) (Scheme 2). The ${ }^{1} \mathrm{H}-\mathrm{NMR}$ spectrum of $\mathbf{5 a}$ exhibited two singlets at $\delta 7.53$ and $\delta 7.07$ for $\mathrm{C}_{3}$ - and $\mathrm{N}-\mathrm{H}$ proton. The structure of $\mathbf{5}$ is fully supported by spectral and analytical data.

In conjunction with this work, we believed that the targeted<smiles>[R]c1cc2c3c([nH]c2c([R])c1[R])C(=O)CCCCC3</smiles><smiles>CCOC(=O)COC</smiles><smiles>[R]c1cc2c3c([nH]c2c([R])c1[R])C(=O)C(=CO)CCCC3</smiles>
1,2 a: $R^{1}=\mathrm{CH}_{3}, \mathrm{R}^{2}=\mathrm{H}, \quad \mathrm{R}^{3}=\mathrm{H}$ b: $\mathrm{R}^{1}=\mathrm{Cl}, \quad \mathrm{R}^{2}=\mathrm{H}, \quad \mathrm{R}^{3}=\mathrm{H}$ c: $\mathrm{R}^{1}=\mathrm{H}, \quad \mathrm{R}^{2}=\mathrm{H}, \quad \mathrm{R}^{3}=\mathrm{CH}_{3}$ d: $R^{1}=H, \quad R^{2}=H, \quad R^{3}=H$


Citation: Vairavelu L, Vellingiri M, Prasad KJR (2016) Synthesis, Biological Evaluation and Structure Activity Relationship of Substituted pyrazolo-, isoxazolo-, pyrimido- and mercaptopyrimidocycloocta[b]indoles. Med chem (Los Angeles) 6: 356-364. doi:10.4172/2161-0444.1000370

pyrimidocycloocta $[b]$ indole $(6)$ was accomplished by the reaction of 7-(hydroxymethylene)-5,7,8,9,10,11-hexahydrocycloocta $[b]$ indol-6one (2) with urea in glacial acetic acid for 5 hours at $120^{\circ} \mathrm{C}$ (Scheme 2). The IR spectrum of $\mathbf{6}$ a revealed the presence of hydroxy and $\mathrm{N}-\mathrm{H}$ functional groups at $3418 \mathrm{~cm}^{-1}$ and $3251 \mathrm{~cm}^{-1}$. The proton NMR spectrum of 6a showed two broad singlets at $\delta 11.68$ and $\delta 9.38$ due to the presence of $\mathrm{C}_{2}-\mathrm{OH}$ and $\mathrm{N}_{13}-\mathrm{H}$. The rest of the aromatic protons appeared between the region $\delta$ 7.54-7.11. The elemental analysis and mass spectral data were compatible with the molecular formula $\mathrm{C}_{17} \mathrm{H}_{17} \mathrm{~N}_{3} \mathrm{O}$.

Further the reaction of 7-(hydroxymethylene)-5,7,8,9,10,11hexahydrocycloocta[b]indol-6-one (2) with thiourea in glacial acetic acid was also investigated with a view to synthesize mercaptopyrimidocycloocta[ $b]$ indole $(7)$ as shown in Scheme 2 . In the IR spectrum of $7 \mathbf{a}$ the absorption band at $1155 \mathrm{~cm}^{-1}$ corresponds to $\mathrm{C}=\mathrm{S}$ group which strongly support the structure of the obtained product as 7 . Furthermore, the ${ }^{1} \mathrm{H}$ NMR gave strong evidence for the formation of compound 7. Moreover, structure 7 was supported by mass spectrum and elemental analysis, which was compatible with assigned structure.

\section{Biology}

Antibacterial activity: The newly synthesized cycloocta[$[b]$ indoles were screened for their in vitro anti bacterial activities against one Gram-positive bacterium Staphylococcus aureus and Gram-negative bacteriae Escherichia coli, Klebsiella pneumonia, Salmonella Typhi, Vibrio cholera and Shigella dysenteriae by the well diffusion method using Streptomycin and Ampicillin as control drugs. The pathogens were cultured on the nutrient agar medium and DMSO was used as solvent and as negative control. The susceptibility was assessed on the basis of diameter of zone of inhibition against gram-positive and gram-negative bacteria. Inhibition zones were measured and compared with the current antibacterial drugs Streptomycin and Ampicillin. The inhibitory activity of $\mathbf{2 a - 7} \mathbf{d}$ against bacteria is summarized in Table 1 , together with the results obtained for streptomycin and Ampicillin which were used as reference drugs.
The antibacterial activity results revealed that the majority of the synthesized compounds showed varying degrees of inhibition against the tested micro organisms. Of particular relevance is that compounds $\mathbf{3 b}, \mathbf{6 b}$ and $\mathbf{7 b}$ had effective antibacterial properties against multidrugresistant strains of S. aureus and E. coli, K. pneumoniae, S. typhi and $V$. cholerae with zone of inhibition values ranging between $27-09 \mathrm{~mm}$ respectively.

The results of the antimicrobial screening lead to the following assumptions about the structural activity relationship (SAR):

- Analysis of the structure-activity relationships shows that the substituent at the $\mathrm{C}_{2}$-position $\left(\mathrm{R}=\mathrm{CH}_{3}, \mathrm{Cl}, \mathrm{H}\right)$ in the intermediate and $\mathrm{C}_{9}-/ \mathrm{C}_{10}-$ position in the cyclized product plays a key role in determining the efficacy of antimicrobial activity.

- The pyrazole moiety [10] in pyrazolocycloocta[b]indoles positively influences in the antibacterial effectiveness, inducing good antimicrobial activity against all the four bacterial pathogens when compared to all other compounds.

- The introduction of electron withdrawing group at the $\mathrm{C}_{2}$ position in the intermediate and $\mathrm{C}_{9}-/ \mathrm{C}_{10}$ - position in the cyclized product contributed to an activity enhancement, with respect to the electron donating $\mathrm{CH}_{3}$ group. The role of electron withdrawing group in improving antimicrobial activities had been reported in the literature [11].

- The introduction of a hydroxyl substituted pyrimidine moiety into the cycloocta[$[b]$ indole core causes decrease in the inhibitory activity against both the gram positive and gram negative bacterial strain when compared with the introduction of mercapto pyrimdine group due to the decrease in lipophilicity [12].

- Compounds with an unsubstituted cycloocta[b]indole ring exhibited only least activity at greater than $160 \mathrm{mg} / \mathrm{ml}$ (data not shown).

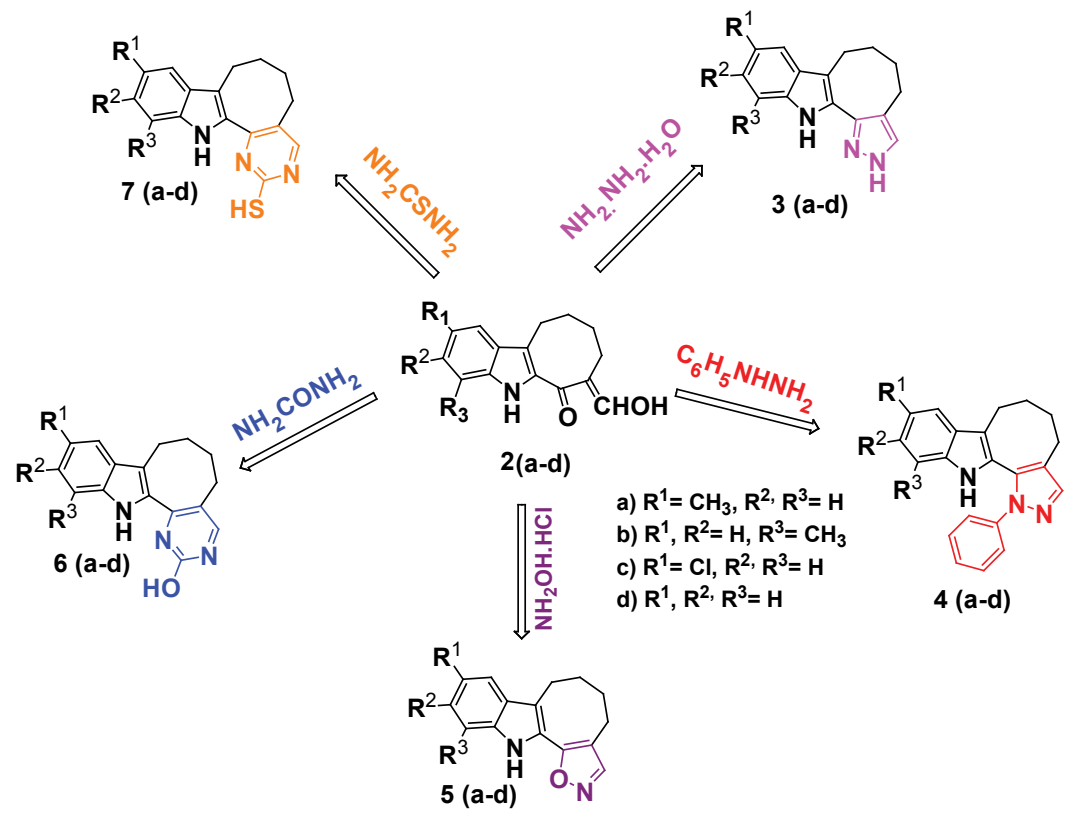

Scheme 2: Synthesis of isoxazolo-, pyrido- and pyrazolo-cycloocta[ $b]$ indoles. 
Citation: Vairavelu L, Vellingiri M, Prasad KJR (2016) Synthesis, Biological Evaluation and Structure Activity Relationship of Substituted pyrazolo-, isoxazolo-, pyrimido- and mercaptopyrimidocycloocta[b]indoles. Med chem (Los Angeles) 6: 356-364. doi:10.4172/2161-0444.1000370

\begin{tabular}{|c|c|c|c|c|c|c|}
\hline \multirow{2}{*}{ Compound } & \multicolumn{6}{|c|}{ Bacteria (zone of inhibition in $\mathrm{mm}$ ) } \\
\hline & ${ }^{a}$ S. aureus & ${ }^{b}$ E. coli & ${ }^{c} K$. pneumoniae & ${ }^{d}$ S. typhi & ${ }^{e}$ V. cholerae & ${ }^{t}$ Shigella sp. \\
\hline $2 a$ & 07 & 08 & 14 & 12 & 9 & 17 \\
\hline 2b & 08 & 07 & 05 & 08 & 09 & 03 \\
\hline 2c & 06 & 03 & 05 & 04 & 11 & 07 \\
\hline $2 d$ & 06 & 05 & 08 & 11 & 9 & 7 \\
\hline 3a & 08 & 07 & 06 & 03 & 11 & 10 \\
\hline 3b & 12 & 11 & 13 & 09 & 27 & 11 \\
\hline $3 c$ & 02 & 03 & 05 & 02 & 12 & 06 \\
\hline 3d & 04 & 11 & 09 & 10 & 07 & 05 \\
\hline $4 a$ & 07 & 09 & 05 & 02 & 10 & 03 \\
\hline $4 b$ & 06 & 08 & 01 & 10 & 09 & 04 \\
\hline 4c & 07 & 11 & 03 & 04 & 11 & 07 \\
\hline 4d & 01 & - & 02 & - & 04 & 03 \\
\hline $5 a$ & 08 & 06 & 05 & 10 & 08 & 07 \\
\hline $5 b$ & 10 & 11 & 10 & 08 & 15 & 04 \\
\hline $5 c$ & 02 & 04 & 07 & 08 & 06 & 03 \\
\hline $5 d$ & - & 06 & - & 11 & - & - \\
\hline $6 a$ & 05 & 08 & 06 & 09 & 04 & 07 \\
\hline 6b & 10 & 09 & 12 & 11 & 15 & 14 \\
\hline $6 c$ & 18 & 14 & 13 & 16 & 19 & 20 \\
\hline $6 d$ & - & - & 08 & 06 & 09 & - Nil- \\
\hline $7 a$ & 04 & 06 & 08 & 03 & 09 & 05 \\
\hline $7 \mathrm{~b}$ & 16 & 16 & 13 & 11 & 26 & 15 \\
\hline $7 \mathrm{c}$ & 07 & 03 & 08 & 05 & 09 & 02 \\
\hline $7 d$ & - & 05 & - & - & 08 & 06 \\
\hline $\begin{array}{c}\text { Streptomycin } \\
(150 \mu \mathrm{g} / \mathrm{mL})\end{array}$ & 09 & - & 12 & 10 & 08 & 12 \\
\hline $\begin{array}{l}\text { Ampicillin } \\
(150 \mu \mathrm{g} / \mathrm{mL})\end{array}$ & 12 & 13 & 11 & - & 17 & 09 \\
\hline
\end{tabular}

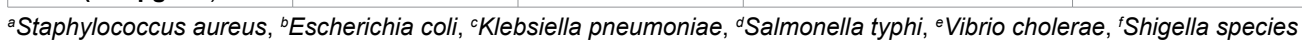

Table 1: Anti-bacterial activity of the products (2a-7d).

Antitumor activity: The antitumor activity of compounds $\mathbf{2 a}$ 7d were assayed with respect to Doxorubicin by evaluating cell proliferation in MCF-7 breast cancer and in A549 non-small cell lung cancer (NSCLC) celllines. After $72 \mathrm{~h}$, all the tested compounds showed significant inhibition of cell proliferation (Table 2). In general, all of the synthesized compounds showed a certain degree of anticancer activity against A549 and MCF7 cell lines. As shown in Table 2, some of the tested compounds showed moderate to potent anticancer activities against both the tested cells. The most interesting compounds $(\mathbf{2} \mathbf{b}-\mathbf{7 b})$ had comparable $\mathrm{IC}_{50}$ to the reference substance, ranging between $7 \pm$ 1.224-24.26 \pm 2.70 against A549 cell line.

Among the intermediates $2(\mathbf{a}-\mathbf{d})$, the promising compound was found to be $\mathbf{2 b}$ which exhibits excellent activity against both the cell lines $\left(\mathrm{A} 549 \mathrm{IC}_{50}=20.06 \pm 3.79 \mu \mathrm{g} / \mathrm{mL}\right.$ and MCF7 $\mathrm{IC}_{50}=21.96 \pm 3.29 \mu \mathrm{g} /$ $\mathrm{mL}$ ). This may be due to the presence of electron withdrawing chloro group at $2^{\text {nd }}$ position. It could be seen from Table 2 that, among the cyclized product, the compound $\mathbf{7 b}$ with electron-withdrawing chloro group at $10^{\text {th }}$ position and $\mathrm{SH}$ groups at $2^{\text {nd }}$ position exhibited the highest cytotoxicity against both $\mathrm{A} 549\left(\mathrm{IC}_{50}=5.02 \pm 2.132 \mu \mathrm{g} / \mathrm{mL}\right)$ and MCF7 $\left(\mathrm{IC}_{50}=12.35 \pm 2.16 \mu \mathrm{g} / \mathrm{mL}\right)$ cell line. The next highest activity was shown by $\mathbf{6 b}$ which is having hydroxy group at $2^{\text {nd }}$ position and chloro group at $10^{\text {th }}$ position with $\mathrm{IC}_{50}$ values $\mathrm{A} 549\left(\mathrm{IC}_{50}=7.00 \pm 1.224 \mu \mathrm{g} / \mathrm{mL}\right)$ and MCF7 $\left(\mathrm{IC}_{50}=11.00 \pm 1.256 \mu \mathrm{g} / \mathrm{mL}\right)$. Compound $3 \mathbf{b}$ showed $\mathrm{IC}_{50}$ values A549 $\left(\mathrm{IC}_{50}=13.31 \pm 2.48 \mu \mathrm{g} / \mathrm{mL}\right)$ and MCF7 $\left(\mathrm{IC}_{50}=15.98 \pm 1.75 \mu \mathrm{g} /\right.$ $\mathrm{mL}$ ) was found to be the next active compound that is having pyrazolo and chloro group. The next highest active compound was $\mathbf{4 b}$ having isoxazolo moiety and chloro group with $\mathrm{IC}_{50}=20.06 \pm 3.79 \mu \mathrm{g} / \mathrm{mL}$ for A549 and $\mathrm{IC}_{50}=21.96 \pm 3.29 \mu \mathrm{g} / \mathrm{mL}$ for MCF cell line. Compound $\mathbf{5 b}$

\begin{tabular}{|c|c|c|}
\hline \multirow{2}{*}{ Compounds } & \multicolumn{2}{|c|}{$\mathrm{IC}_{50}(\mu \mathrm{g} / \mathrm{mL})$} \\
\hline & A549 ${ }^{a}$ & MCF7 $^{b}$ \\
\hline $2 a$ & $28.62 \pm 2.43$ & $27.34 \pm 2.44$ \\
\hline $2 b$ & $20.06 \pm 3.79$ & $21.96 \pm 3.29$ \\
\hline $2 c$ & $38.84 \pm 4.33$ & $37.79 \pm 4.18$ \\
\hline 2d & $44.27 \pm 3.64$ & $49.45 \pm 2.34$ \\
\hline $3 a$ & $26.24 \pm 1.33$ & $30.41 \pm 3.35$ \\
\hline $3 b$ & $13.31 \pm 2.48$ & $15.98 \pm 1.75$ \\
\hline $3 c$ & $47.26 \pm 2.76$ & $35.77 \pm 1.59$ \\
\hline $3 d$ & $43.16 \pm 2.65$ & $47.56 \pm 3.81$ \\
\hline $4 a$ & $28.63 \pm 1.40$ & $29.96 \pm 3.71$ \\
\hline $4 b$ & $20.06 \pm 3.79$ & $21.96 \pm 3.29$ \\
\hline $4 c$ & $42.32 \pm 2.56$ & $37.14 \pm 3.83$ \\
\hline $4 d$ & $49.18 \pm 1.80$ & $48.26 \pm 1.17$ \\
\hline $5 a$ & $48.21 \pm 1.85$ & $50.41 \pm 2.43$ \\
\hline $5 b$ & $24.26 \pm 2.70$ & $27.23 \pm 3.47$ \\
\hline $5 c$ & $32.00 \pm 3.51$ & $25.22 \pm 2.04$ \\
\hline $5 d$ & $45.88 \pm 2.10$ & $54.61 \pm 3.84$ \\
\hline $6 a$ & $22.79 \pm 2.67$ & $30.13 \pm 3.74$ \\
\hline $6 b$ & $7.00 \pm 1.224$ & $11 \pm 1.256$ \\
\hline $6 c$ & $26.21 \pm 1.262$ & $32 \pm 1.220$ \\
\hline $6 d$ & $30.16 \pm 3.435$ & $45 \pm 2.478$ \\
\hline $7 a$ & $24 \pm 3.131$ & $31 \pm 1.334$ \\
\hline $7 b$ & $5.02 \pm 2.132$ & $12.35 \pm 2.16$ \\
\hline $7 c$ & $29.12 \pm 1.456$ & $34 \pm 2.126$ \\
\hline $7 d$ & $35.12 \pm 3.546$ & $46 \pm 2.417$ \\
\hline Doxorubicin & $6.00 \pm 1.237$ & $12.355 \pm 2.38$ \\
\hline
\end{tabular}

aHuman Lung adenocarcinoma, ${ }^{b}$ Human Breast adenocarcinoma Table 2: In vitro cytotoxic activity of the products (2a-7d) 


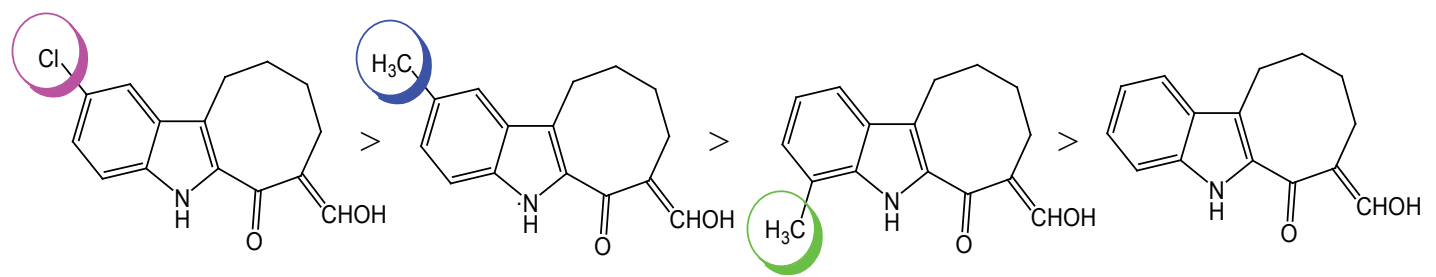

Figure 2: The decreasing order of activity of intermediates.
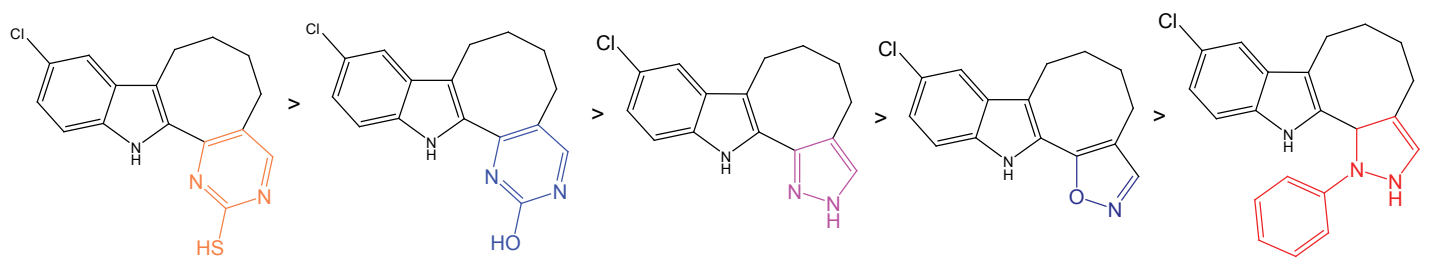

Figure 3: The decreasing order of activity of cyclized products.

having phenyl group at $1^{\text {st }}$ position and chloro group at $9^{\text {th }}$ position was found to exhibit slightly decreased anticancer potency against (A549 $\mathrm{IC}_{50}=24.26 \pm 2.70 \mu \mathrm{g} / \mathrm{mL}$ and MCF7 $\left.27.23 \pm 3.47\right)$ cell line.

Compounds 7a, 6a, 3a, 4a, 5a, 7c, 6c, 3c, $4 \mathbf{c}$ and $5 \mathbf{c}$ showed moderate activity ranging between $22.79 \pm 2.67-49.45 \pm 2.34$ against both the cell lines. Compounds $\mathbf{7 d}, \mathbf{6 d}, \mathbf{3 d}, \mathbf{4 d}$ and $\mathbf{5 d}$ showed least activity ranging between $35.12 \pm 3.54-54.61 \pm 3.84$.

Structure activity relationship: The structure-activity relationship analysis of the data reported in Table 2 shows that,

- Among the intermediates as well as cyclized products, compounds having chloro group was found to be the most active compound compared to the non-halogenated compounds. Out of the intermediates formed, compound $\mathbf{2} \mathbf{b}$ exhibited excellent cytotoxicity. The reason for the efficacy was attributed to the stronger electron with drawing nature of chorine [13] that is presented in compound $\mathbf{2} \mathbf{b}$. For the intermediates the order of activity was shown in Figure 2.

- Among the cyclized products, compound $\mathbf{7 b}$, was found to be the promising one having chloro group at the $10^{\text {th }}$ position and $\mathrm{SH}$ group at $2^{\text {nd }}$ positon. This may be due to the presence of mercapto pyrimdo [14,15] moiety which enhances the cytotoxic activity. The next potent compound was $\mathbf{6 b}$ that contains hydroxyl group at $2^{\text {nd }}$ positon and chloro group at the $10^{\text {th }}$ position. Compound $\mathbf{3 b}$ showed next highest activity which is having pyrazolo moiety and chloro group. The next active compound was $\mathbf{4 b}$ that is having isoxazolo group. The least activity was shown by compound $\mathbf{5 b}$ that contains substituted phenyl pyrazolo group. For the cyclized products the order of activity was shown in Figure 3.

\section{Conclusion}

Novel hetero annulated cycloocta[ $[b]$ indoles were synthesized by efficient synthetic routes and their anti bacterial and anti proliferative activities were assessed. The chloro substituted cycloocta[$[b]$ indoles exhibited high anti bacterial activity than their methyl substituted and unsubstituted counter parts. Furthermore, most of them had high anti proliferative activity against breast MCF-7 and lung A549 tumor cell lines. $\mathbf{7 b}$ emerged as the most active antibacterial compound against multidrug-resistant $S$. aureus and the most potent antiproliferative compound against A549 and MCF-7 cells.
While the investigation at the molecular level identified only in part the targets and the binding modes of these new molecules need to be further elucidated, the combination of potent activity against Gram positive bacteria and cancer cell lines make these agents of interest in the search for potential cancer chemotherapeutics. These compounds, possessing both anticancer and antibacterial activity, have a promising therapeutic potential due to their selective cytoxicity coupled with the ability to reduce the danger of bacterial infections in the frequently immune compromised cancer patient. Furthermore, the screening for anti proliferative properties showed that all products may have a good future as new potent antitumor agent.

To the best of our knowledge, this is the first report on the bio active potential of cycloocta[b]indole counter parts against the A549 and MCF-7 cancer cell lines with $\mathrm{IC}_{50}$ value $5 \pm 2.132$. This result could be used as a basis for the development of a structure oriented drug discovery program and further study is underway.

\section{Acknowledgements}

Dr. KJ Rajendra Prasad is grately acknowledged UGC-Emeritus fellowship for research. We thank the IIT-Madras, Chennai and IISc-Bangalore, India for their support in spectral studies.

\section{References}

1. Hibino S, Choshi T (2001) Simple indole alkaloids and those with a non rearranged monoterpenoid unit. Nat Prod Rep 18: 66-87.

2. Keawpradub N, Eno-Amooquaye E, Burke PJ, Houghton PJ (1999) Cytotoxic activity of indole alkaloids from Alstonia macrophylla. Planta Med 65: 311-315.

3. Mayerl F, Hesse M (1978) Macrocarpamin, ein neues Bisindolalkaloid aus Alstonia macrophylla Mittelung über organische Naturstoffe. Helv Chim Acta 61: 337-351.

4. Keawpradub N, Kirby GC, Steele JC, Houghton PJ (1999) Antiplasmodial activity of extracts and alkaloids of three Alstonia species from Thailand. Planta Med 65: 690-694.

5. Wright CW, Allen D, Cai Y, Phillipson JD, Said JM, et al. (1992) In vitro antiamoebic and antiplasmodial activities of alkaloids isolated from Alstonia angustifolia roots. Phytother Res 6: 121-124

6. Wetzel S, Bon RS, Kumar K, Waldmann H (2011) Biology-oriented synthesis Angew Chem Int Ed Engl 50: 10800-10826.

7. Nören-Müller A, Wilk W, Saxena K, Schwalbe H, Kaiser M, et al. (2008) Discovery of a new class of inhibitors of Mycobacterium tuberculosis protein tyrosine phosphatase B by biology-oriented synthesis. Angew Chem Int Ed Engl 47: 5973-5977. 
Citation: Vairavelu L, Vellingiri M, Prasad KJR (2016) Synthesis, Biological Evaluation and Structure Activity Relationship of Substituted pyrazolo-, isoxazolo-, pyrimido- and mercaptopyrimidocycloocta[b]indoles. Med chem (Los Angeles) 6: 356-364. doi:10.4172/2161-0444.1000370

8. Perkin WH, Plant SGP (1928) Stereoisomerism in polycyclic systems. J Chem Soc 2583-2590.

9. Sundberg RJ, Yamazaki T (1967) Rearrangements and ring expansions during the deoxygenation of beta, beta-disubstituted o-nitrostyrenes. J Org Chem 32: 290-294.

10. Boyer FE, Vara Prasad JVN, Choy AL, Chupak B, Dermyer MR, et al. (2007) Synthesis and SAR of novel conformationally-restricted oxazolidinones possessing Gram-positive and fastidious Gram-negative antibacterial activity. Part 1: Substituted pyrazoles. Bioorg Med Chem Lett 17: 4694-4698.

11. Sharma P, Rane N, Gurram VK (2004) Synthesis and QSAR studies of pyrimido[4,5-d]pyrimidine-2,5-dione derivatives as potential antimicrobial agents. Bioorg Med Chem Lett 14: 4185-4190.
12. Završnik D, Selma Š, Dženita S (2011) Synthesis, structure and antibacterial activity of 3-substituted derivatives of 4-hydroxycoumarin. Period Biol 113: 93-97.

13. Vairavelu L, Zeller M, Rajendra Prasad KJ (2014) Solvent-free synthesis of heteroannulated carbazoles: A novel class of anti-tumor agents. Bio Organic Chem 54: 12-20.

14. Babu V, Harinadha Kumar P, Senthil Srinivasan KK, Bhat GV (2004) Synthesis, antitumor and antibacterial activities of certain substituted pyrimidines bearing benzofuran. Indian J Pharm Sci 66: 647-652.

15. Blagosklonny MV, El-Deiry WS (1996) In vitro evaluation of a p53-expressing adenovirus as an anti-cancer drug. Int J Cancer 67: 386-392. 